ANL-5798

Reactors - Power

ARGONNE NATIONAL LABORATORY

P.O. Box 299

Lemont, Illinois

POWER TRANSEER FUNCTIONS OF THE EBWR OBT AINED USING A SINUSOIDAL REACTIVITY DRIVING FUNCTION

by

J.A. DeShong, Jr.

Reactor Engineering Division

Experiments performed by:

R. V.Batch

W. C. Lipinski

J. A. DeShong, Jr.

W. H. McCorkle

A. S. Gibson

J. Pohlman

V.C. Hall

J.A. Thie

J.M. Harrer

E. A. Wimunc

A. Hirsch

LRRO Personne1

N. A. Kershaw

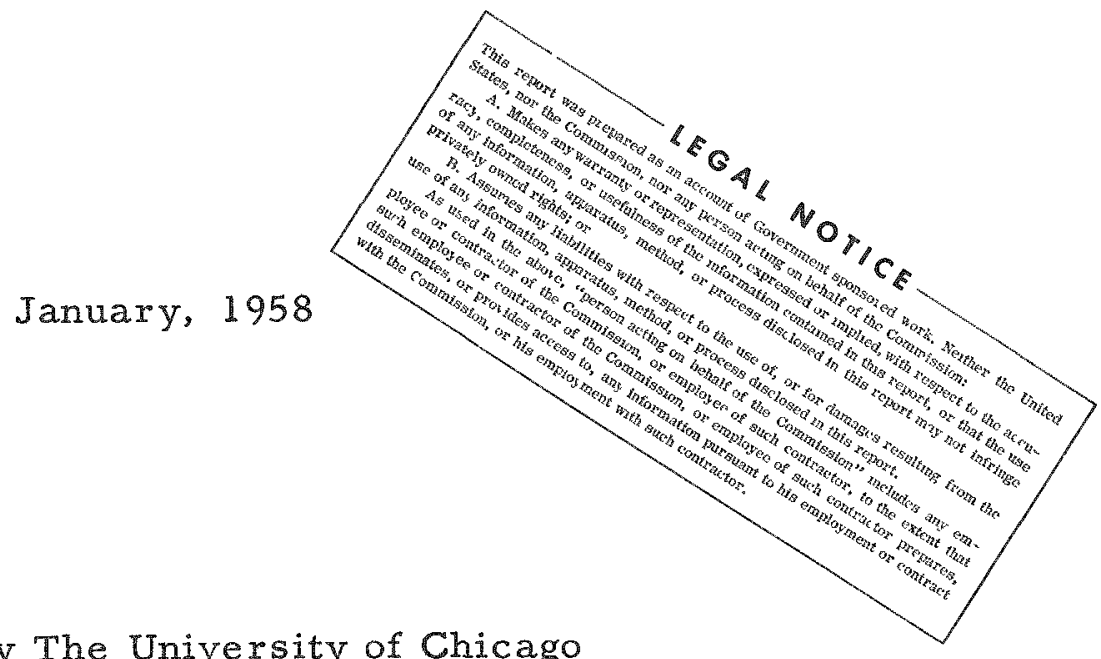

Operated by The University of Chicago

under

Contract W-31-109-eng-38 


\section{DISCLAIMER}

This report was prepared as an account of work sponsored by an agency of the United States Government. Neither the United States Government nor any agency Thereof, nor any of their employees, makes any warranty, express or implied, or assumes any legal liability or responsibility for the accuracy, completeness, or usefulness of any information, apparatus, product, or process disclosed, or represents that its use would not infringe privately owned rights. Reference herein to any specific commercial product, process, or service by trade name, trademark, manufacturer, or otherwise does not necessarily constitute or imply its endorsement, recommendation, or favoring by the United States Government or any agency thereof. The views and opinions of authors expressed herein do not necessarily state or reflect those of the United States Government or any agency thereof. 


\section{DISCLAIMER}

Portions of this document may be illegible in electronic image products. Images are produced from the best available original document. 


\section{TABLE OF CONTENTS}

Page

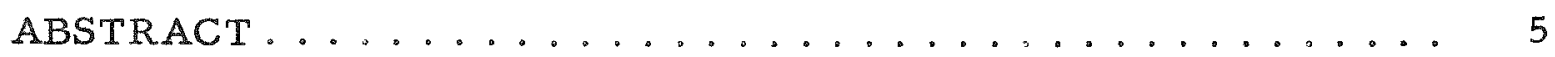

I. INTRODUCTION ...................... 5

II. THE ZERO-POWER REACTOR TRANSFER FUNCTION ... 6

III. THE POWER REACTOR TRANSEER FUNCTION ........

IV. MEASUREMENT TECHNIQUE ................ 11

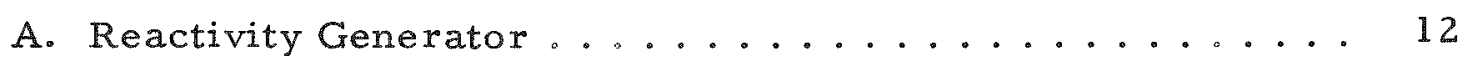

B. Wave Analyzer ....................... 12

C. Special Steam Instrumentation............... 13

D. Reactivity Calibration and Curve Normalization ...... 13

V. POWER TRANSFER FUNCTIONS .............. 15

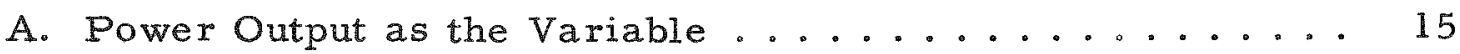

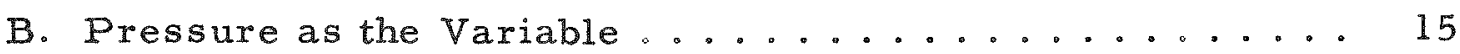

C. Rod Bank as the Variable ................ 15

D. Multiple Parameter Variation .............. 17

VI. CONCLUSIONS. ...................... 17 APPENDICES:

Appendix A: Reactivity Input Function Generator........ 19 Appendix B: Wave Analyzer................ 27

Appendix C: Steam Instrumentation. ............. 29 


\section{LIST OF FIGURES}

No

\section{Title}

$\underline{\text { Page }}$

1 Zero-Power Frequency Response ............ 7

2 Schematic of Power-to-Reactivity Feedback ......... 9

3 EBWR Power-to-Reactivity Feedback Diagram ........ 10

4 Control Rod Arrangement ................ 13

5 Effects of Power on Frequency Response .......... 16

6 Effects of Pressure on Frequency Response ......... 16

7 Effects of Rod Bank Position on Frequency Response ..... 16

8 Effects of Multiple Parameter Variations on Frequency Response ........................ 18

9 Hydraulic Servo Transmission . . . . . . . . . . 20

10 Reactivity Gene rator Gear Transmission .......... 21

11 Reactivity Generator Amplitude Selector .......... 22

12 Transfer Function Reactivity Drive............. 23

13 Reactivity Generator Drive Assembly ........... 24

14 Block Diagram of Wave Analyzer ............ 28

15 Correlator Schematic Diagram .............. 28

16 Correlator Calibration .................. 32

17 Detector Schematic Diagram .............. 33

18 Analyzer Servo Plate ................... 35

19 Input Function Frequency Controller and Wave

20 Flowmeter $\mathrm{Transducer} \ldots \ldots \ldots \ldots \ldots \ldots . \ldots . \ldots 40$

21 AC Amplifier - Demodulator for Flow Transducer....... 41

22 Micrometer-Operated Rebalancing Differential

Transduce $\ldots \ldots \ldots \ldots \ldots . . . \ldots . . . . . . .42$

23 Frequency Response of Carrier Amplifier .......... 42

24 Over-all Phase Shift Demodulated Output/Modulation of Carrier Input . . . . . . . . . . . . . . 43

25 Natural Frequency of Flowmeter vs Length of $1 / 2$-inch

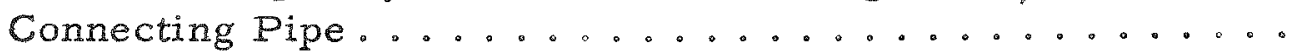




\section{LIST OF FIGURES}

No.

Title

Page

26 Phase Shift of Transducer and Amplifier with Three feet of 1/2-inch Pipe Connections and Valve Set for Damping Ratio $=0.4 \ldots \ldots \ldots$

27 Differential Pressure of EBWR Flow Nozzles ........ 44

28 Feedwater Flowmeter Installation.............. 45

29 Steam Flowmeter Installation. .............. 46

30 Schematic of Modified Pressuregraph Circuit . . . . . . 48

31 Pressure Instrumentation ................ 49

\section{LIST OF TABLES}

No.

Title

Page

I Nuclear Constants of EBWR at Zero Power..........6

II Frequency Response Measurements - Run A........ 8 


\title{
POWER TRANSFER FUNCTIONS OF THE EBWR OBTAINED USING A SINUSOIDAL REACTIVITY DRIVING FUNCTION
}

\author{
By
}

J.A. DeShong, Jre

\begin{abstract}
A series of reactor frequency response measurements, relating flux or power level to a reactivity input function, were made to evaluate reactor stability for different values of power parameters. These parameters included: power level, steam pressure, and control rod position. The results were extrapolated to predict EBWR stability at higher operating powers. The experimental data may also be used to evaluate the thermodynamic and hydraulic constants.
\end{abstract}

\section{INTRODUCTION}

The kinetic behavior of a direct-cycle boiling reactor power plant. such as the EBWR, is strongly influenced by the power effects on reactivity 1,2 inherent in the mechanical and thermodynamic design. These include steam voids due to boiling, density changes of water due to temperature variation. and feed-water temperature and flow changes.

The kinetic behavior of such a reactor can be expressed in terms of a transfer function. ${ }^{3}$ The transfer function as used here describes the amplitude and phase relation of the sinusoidal variation in flux or power output with respect to the sinusoidal reactivity input driving function. Such transfer functions are particularly useful in stability studies of complex feedback systems. $4,5,6$ The functions presented here represent measurements for many different values of reactor parameters, e.g., power level,

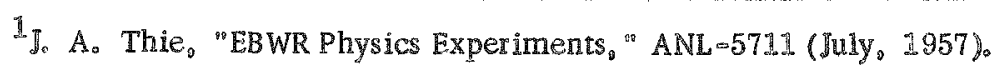

2. A. DeShong, Iro, "Styrofoam Simulation of Boiling and Temperature Effects in the EBWR Cold Critical Experiments," ANL 56697 (Mard, 1957)

3

Jo $M_{0}$ Harrer, R。E。 Boyar, and Darwin Krucoff, "Transfer Function of Argonne CP $\approx 2$ Reactor, Nucleonics, 10 (August) $32 \times 36$ (1952)

${ }^{4} J_{0} M_{0}$ Harrer, and $J_{0} A_{\circ}$ Deshong, JPo "Discontinuous Servo for Control of Power Reactors, Nucleonics。 12 (January), 44×51 (1954)

${ }^{5} \mathrm{H}_{0}$ W. Bode, "Network Analysis and Feedback Amplifier Designs, "D。 Van Nostrand Co。 Inc。 New York (1945\%

$6_{\mathrm{H}}$. Chestmut and R. W。 Mayer "Servomechanisms and Regulating System Design, " Jo Wiley and Sons, Inc。 (New York 1951) 
pressure, and core length. They will be used in an attempt to extrapolate and predict EBWR stability at higher operating powers. The maximum stable power density is set, in large measure, by the effect of the power feedback parameters on the zero-power characteristics. The prerequisite to the calculation of these parameters using the power transfer functions is the determination of the function at zero power.

\section{THE ZERO-POWER REACTOR TRANSFER FUNCTION}

Given certain of the reactor nuclear constants, the zero-power reactor kinetics can be readily calculated and expressed in terms of a transfer function.

The nuclear constants for EBWR at zero power $(6 \mathrm{kw})$ are listed in Table I.

Table I

NUCLEAR CONSTANTS OF EBWR AT ZERO POWER

Delayed Neutron Constants:

\begin{tabular}{|c|c|}
\hline$\lambda_{i}$ & $\beta_{i}$ \\
\hline 0.01246 & 0.00025 \\
\hline 0.0315 & 0.00166 \\
\hline 0.1535 & 0.00213 \\
\hline 0.456 & 0.00241 \\
\hline 1.612 & 0.00085 \\
\hline 14.3 & 0.00025 \\
\hline
\end{tabular}

Mean Effective Neutron Lifetime $(\ell *): 6 \times 10^{-5} \mathrm{sec} * *$

*Private Communication, J.A. Thie, ANL

These values and the method of reference (3) were used to calculate the frequency response shown in Fig. 1. The "gain" ordinate represents $20 \log _{10}$ of the ratio obtained by dividing the flux or power output peak amplitude, $N_{p}$ (expressed as a fraction of the average flux value, $N_{0}$ ) by the ratio of the input reactivity peak amplitude, $\delta \mathrm{k}_{\mathrm{p}}$, to the total delayed neutron fraction, $\beta_{\mathrm{T}}$. Mathematically, this may be shown as

$$
\text { Gain }=20 \log _{10} \frac{N_{\mathrm{p}} / N_{\mathrm{o}}}{\delta \mathrm{k}_{\mathrm{p}} / \beta_{\mathrm{T}}} \quad \text { decibels. }
$$

The use of decibels is an engineering usage adopted for convenience in plotting. The "phase" ordinate is simply the phase of $N_{p}$ with respect to $\delta k_{p}$, in
degrees. 
The experimentally determined values of amplitude and phase are listed under Test 1 of Table II and plotted on Fig. l. The amplitude $\delta k_{p}$ required to normalize these data was determined by period measurements with the reactivity generator at the maximum limits of its stroke. This generator and the equipment used to measure the ratio $\mathrm{N}_{\mathrm{p}} / \mathrm{N}_{\mathrm{o}}$ will be described later.
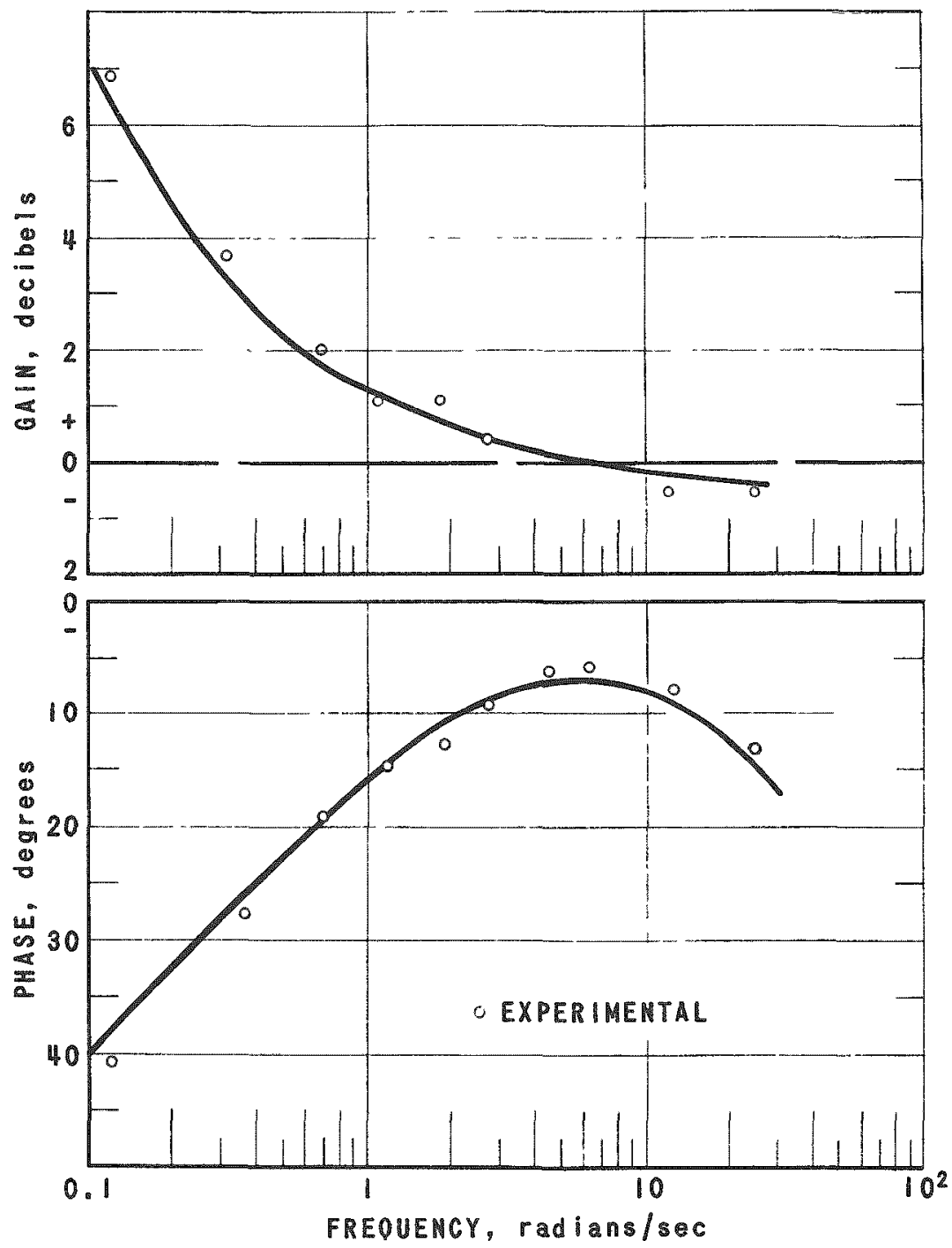

$\begin{array}{ll}\text { POWER, WW } & \text { ZERO }(6 \mathrm{~kW}) \\ \text { PRESSURE, PSI } & 150 \\ \text { BORON } & \text { MO } \\ \text { CENTER ROD, in. } & 13.6 \\ \text { 8-ROD BAHK, in. } & 14.5 \\ \text { STEAM BYPASS } & \text { MANUAL } \\ \text { PEAK REACTIVITY, \% FOR } & 0.087 \\ \text { I-In. PEAK STROKE } & \end{array}$

FIG. I

ZERO POWER FREQUENCY RESPONSE 


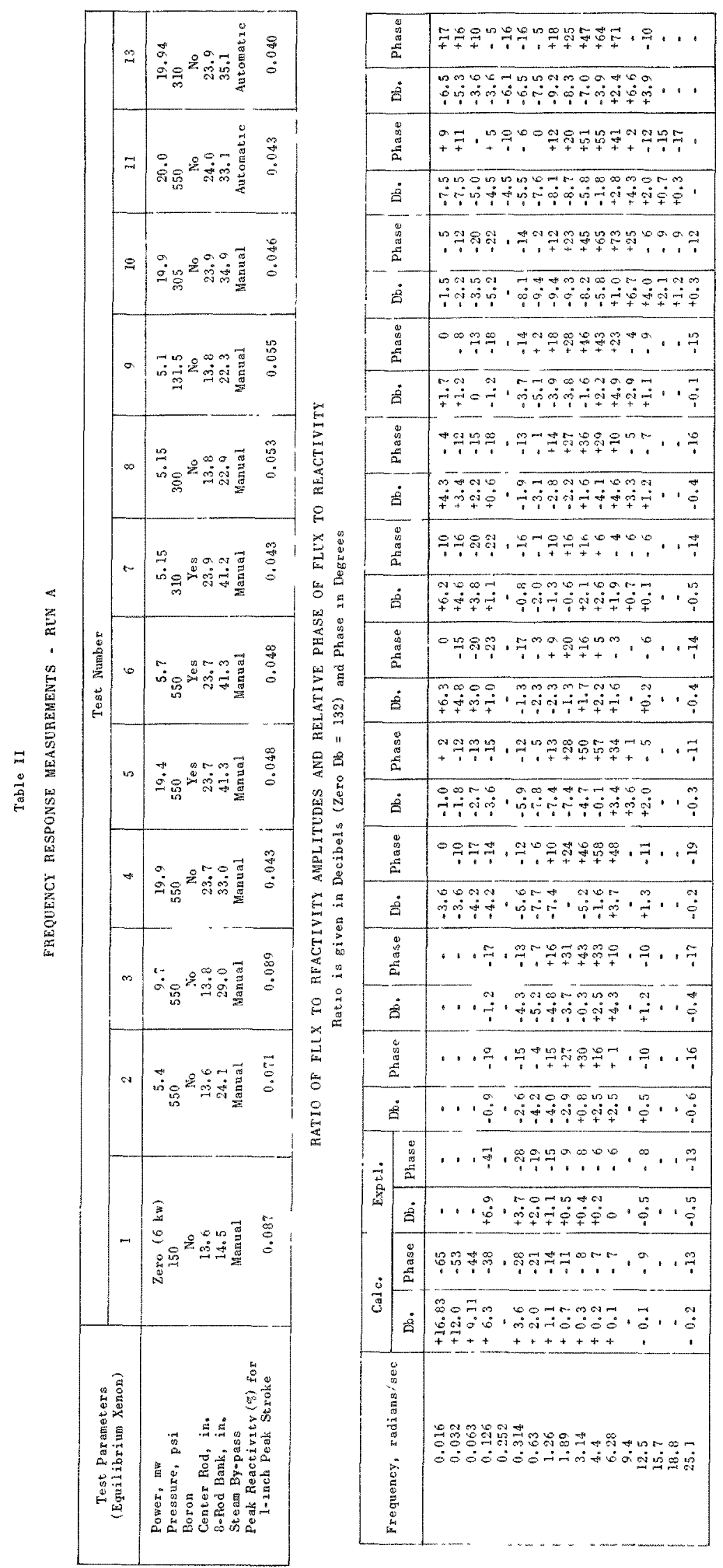




\section{THE POWER REACTOR TRANSFER FUNCTION}

The power reactor transfer function is simply the zero-power function modified by power-to-reactivity feedback. The feedback schematic is shown in Fig. 2.

REACTIVITY

INPUT

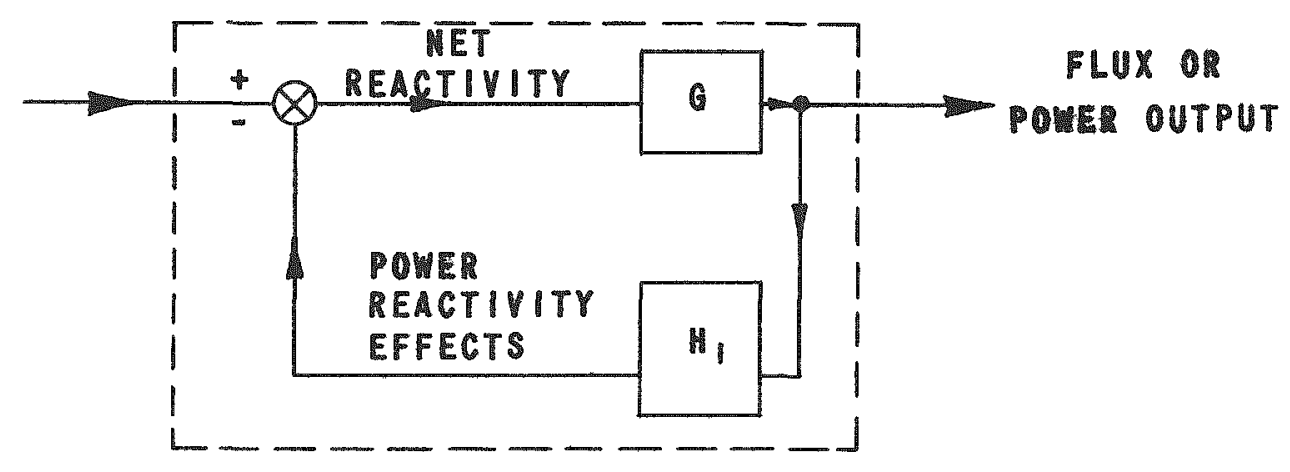

FIG. 2

SCHEMATIC OF POWER-TO-REACTIVITIY FEEDBACK

$G$ represents the zero power function, and

$\mathrm{H}_{1}$ is the transfer function which represents the reactor internal power-to-reactivity feedback for a specified set of reactor power parameters.

Then:

$$
P_{1}=\frac{G}{1+G H_{1}}=\frac{\text { Flux Output }}{\text { Reactivity Input }},
$$

where $P_{1}$ is the power reactor transfer function for the power parameter values specified. Various well-known techniques can be employed to yield quantitative stability for the mode of operation it represents. $4,6,7$

$P_{1}$ could be calculated and stability predicted if $H_{1}$ were known. However, $\mathrm{H}_{1}$ is difficult to calculate quantitatively from thermodynamic data, and the nature of the direct-cycle concept makes specific measurement extremely difficult. Another method is to measure $P_{1}$ and calculate $\mathrm{H}_{1}$ using the relation:

$$
H_{1}=P_{1}^{-1}-G^{-1}
$$

\footnotetext{
${ }^{7}$ M. A. Schultz, "Control of Nuclear Reactors and Power Plants, "McGraw-Hill Book Co. Inc., (New York: 1955)
} 
which is simply a rearrangement of Eq. (2). Trends in $\mathrm{H}_{1}$ can be obtained and used to predict stability. The latter technique was used on EBWR and led to the measurements reported herein.

A simplified power-to-reactivity feedback diagram for EBWR is shown in Fig. 3.

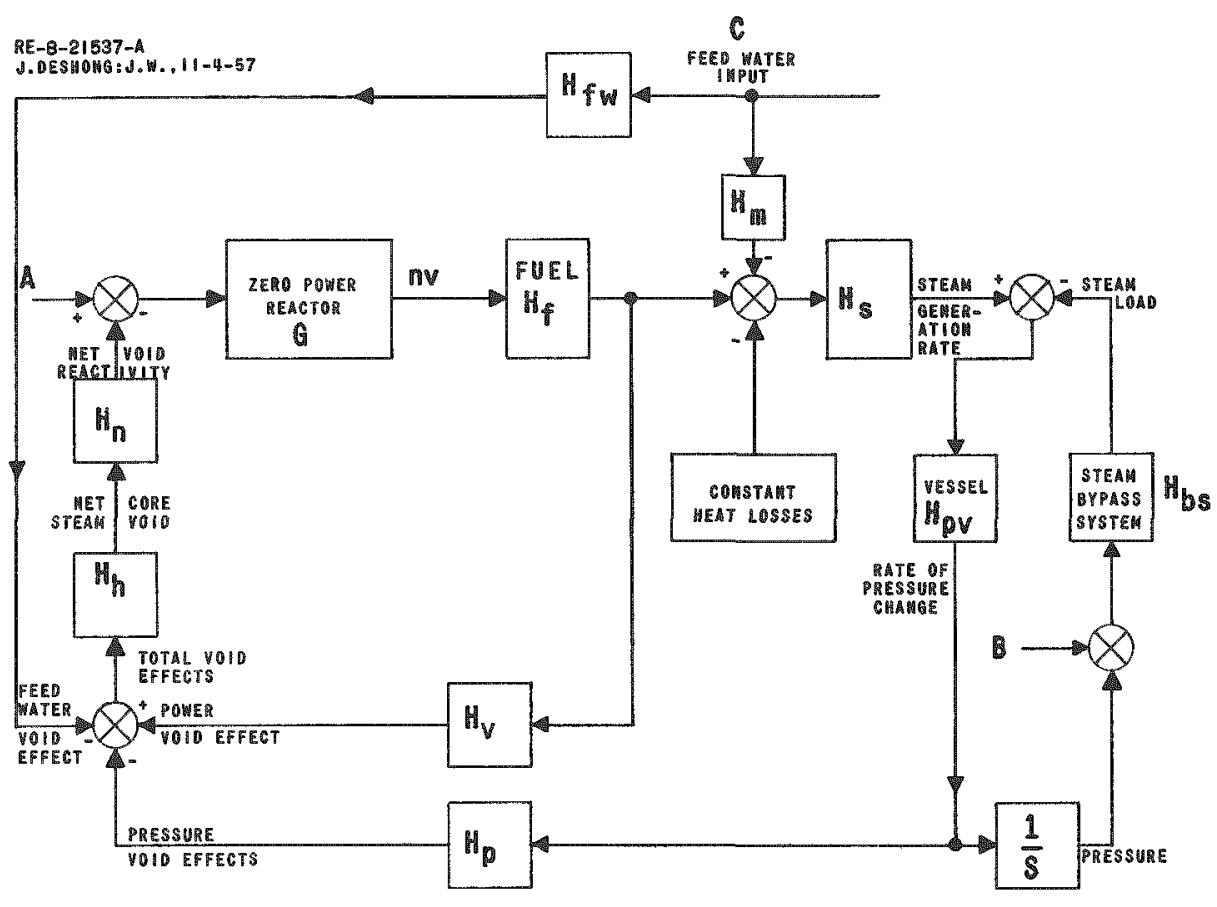

FIG. 3

EBWR POWER-TO-REACTIVITY FEEDBACK DIAGRAM

Each $\mathrm{H}$ in Fig. 3 is a transfer function representation of a power effect. $H_{\text {fw }}$ is the effect on voids which results from core subcooling by the feed water. $\mathrm{H}_{\mathrm{m}}$ is the heat consumed in feed-water heating after injection. C represents the feed-water injection which is held constant at the average rate of flow required for the power output level of a particular experiment. $H_{f}$ is the heat transfer characteristic for heat flow from the generation point (fuel element) to and including its absorption in the coolant. It includes the factor relating heat generation and flux. $\mathrm{H}_{\mathrm{V}}$ is the relation between power and steam or void formation internal to the core. $\mathrm{H}_{\mathrm{s}}$ determines steam generation from the net heat. $H_{p y}$ represents the pressure vessel characteristics which determine rate of pressure change when steam generation rate and steam load are not equal. $\mathrm{Hbs}_{\mathrm{b}}$ is the dynamic characteristic of the automatic steam bypass system. 8 Since the steam load was controlled by manual bypass, $\mathbb{H}_{\mathrm{bs}}$ would have zero input. $\mathrm{H}_{\mathrm{p}}$ is a

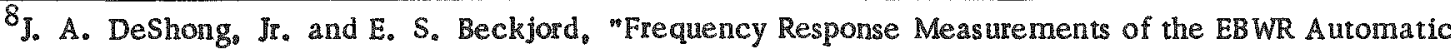
Steam Bypass Valve Control System, "ANL -5726 (June, 1957) 
complex function which represents the void effects due to pressure. These include temperature coefficient, flashing, and void boundary change. $H_{h}$ is the natural recirculation dynamic effect on total void which determines the net core steam void. $H_{n}$ is the relation between net void reactivity and net core steam void. G represents the zero-power function given in Fig. 1 .

The complexity of the actual reactor feedbacks as compared to Fig. 2 makes the analytic separation of the individual feedback functions very difficult for the case where the flux, $n v$, is measured for a sinusoidal reactivity driving function inserted at $A$. Utilization of an input at $B$ to vary steam flow in synchronism with the reactivity input $A$ would, by shifting the phase and magnitude of $B$ with respect to $A$, make it possible to hold pressure constant and measure the $\mathrm{H}_{\mathrm{V}}$ loop with $\mathrm{C}$ constant. In a similar manner, it would also be possible to hold $\mathrm{nv}$ constant and measure the $\mathrm{H}_{\mathrm{p}}$ loop. These experiments would require two very accurately synchronized servo systems. The feasibility of such an application is being investigated.

Stability determination was the main objective of the tests. Investigation of pressure effects indicated that at fxequency values in excess of 2 or 3 radians/second the pressure feedback loop, $\mathrm{H}_{\mathrm{p}}$, can be neglected, leaving only the power void loop, $\mathrm{H}_{\mathrm{V}}$, since feed-water input, $\mathrm{C}$, is held constant. Preliminary tests without automatic pressure control showed that the frequency of maximum resonant peak response was in excess of $5 \mathrm{radians} / \mathrm{second}$, making the peak response almost independent of pressure variation. Then system stability, which can be expressed in terms of this peak response, can be determined without automatic pressure control, using only a reactivity driving function at $A$ and measuring flux, nv. This was the method used in all tests except No. 11 and No. 13; these were made with automatic bypass system operation to obtain preliminary information on pressure effects.

\section{MEASUREMENT TECHNIQUE}

A high degree of accuracy is required for measurements which will be used for calculations wherein $H$ is derived from the $G$ and $P$ functions, particularly where $P$ is nearly equal to the $G$ function. Physically, $P$ must become equal to $G$ at high frequencies. since the power feedback becomes very small and GH becomes small with respect to one.

$$
P_{1}=\frac{G}{1+G H_{1}} \cong G \quad \text { for } G_{1} \ll 1
$$

Phase errors of a few degrees and amplitude errors of several per cent can change the calculated value of $\mathrm{H}_{1}$ by very large amounts. Accurate determination of the frequency, $\omega$, is also important, particularly where the phase shift is changing rapidly with frequency. The means used to attain the desired degree of accuracy are described below. 


\section{A. Reactivity Generator}

The reactivity forcing function was applied by a special rod drive installed in place of the regular central control rod drive. The drive consisted of a variable-displacement bell crank driven by a combination of mechanical and hydraulic transmissions to provide a frequency range of 0.01 to 25 radians/second. The connecting rod, which was very long with respect to the crank displacement, generated an accurate sinusoidal control rod stroke and produced the desired sinusoidal reactivity variation. Owing to the large forces of pressure and inertia, a spring was used to bias out the pressure forces and resonate with the inertia to reduce the horsepower requirements.

A detailed description of the generator components and performance characteristics is given in Appendix $A$.

\section{B. Wave Analyzer}

Graphic recording methods, although simple, do not meet the accuracy requirements indicated above. Some type of wave analyzer is needed to measure the amplitude ratio and phase displacement of the fundamental flux wave with respect to the reactivity forcing function. In fact, the boiling noise in a boiling reactor flux output ranges up to a peak value of $5 \%$, or more, of the average flux value. The amplitude of the reactivity input is limited by both the reactivity drive power requirements and the necessity for maintaining a small input to preserve linearity. ${ }^{3}$ Thus the output flux variation, which is proportional to the input reactivity variation, often has a peak value of less than $5 \%$ of the average flux value, resulting in signal-to-noise ratios of less than one in many cases. In order to measure to $\pm 5 \%$ in amplitude and \pm 2 degrees in phase in such unfavorable circumstances, it is necessary to employ a wave analyzer which will measure only the fundamental component of the flux wave and compare it with the reactivity forcing function.

Wave analyzers with sufficiently narrow bandwidth to be used in the very low frequency range of 0.01 to $25 \mathrm{radians} / \mathrm{second}$ are not readily available commercially. The wave analyzer used was developed at Argonne. Operation is based on a correlation technique in which the reactor flux output variation measured by an ion chamber is multiplied by a vector which is correlated to the reactivity driving function in both amplitude and phase. It is possible to select a correlation which reduces the fundamental component of the multiplied signal to zero, leaving only a small second harmonic plus any noise present in the original flux signal. Feedback control is used to adjust the amplitude correlation. Phase shift correlation is attained by a mechanical differential. Narrow band width is achieved by passing the multiplied signal through a band-pass filter adjusted to pass only the fundamental frequency. This strongly attenuates everything but 
the fundamental component which then may be reduced to zero by proper correlation adjustment. A complete description of the wave analyzer circuit is given in Appendix B.

\section{Special Steam Instrumentation}

The necessity for providing high-resolution, fast-responding, steam instrumentation stems from the limitations imposed by the nonlinearities of the reactor zero-power kinetics and the power-to-reactivity feedback loops. The peak magnitude of dynamic variation in reactor parameters must be limited to about $10 \%$ in order to provide a linear smallsignal measurement which can be used for stability studies. The variation is small; therefore instruments of high resolution are necessary. Tentative minimum specifications required resolution and accuracy of one part in a thousand for maximum pressure and flow, and a frequency response bandwidth of 5 cycles/second. The bandwidth was selected to eliminate the necessity for applying large corrections to the data.

Since the installed EBWR plant instruments were not commensurate with the above requirements, development work was undertaken to produce the necessary instruments. These are described in detail in Appendix C.

\section{Reactivity Calibration and Curve Normalization}

Figure 4 is an elevation of the reactor core which shows the control rod arrangement used in the tests. The rod-bank position is given in inches of withdrawal of rods 1 through 8 as required for a given power level.

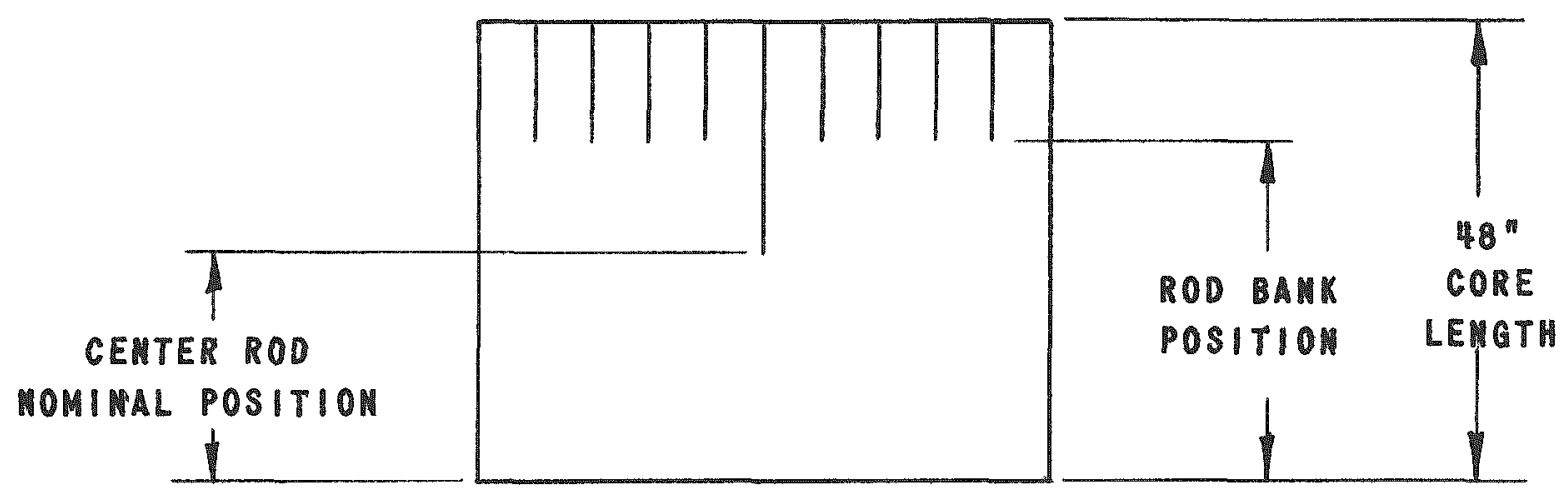

FIG. 4

CONTROL ROD ARRANGEMENT 
The center rod projects from the rod bank and occupies one of two fixed alternate nominal positions, one at $14 \mathrm{in}$. withdrawn and the other at 24 in. withdrawn. This was done to give the center rod greater reactivity effectiveness, thereby reducing the required stroke amplitude and the power input to the reactivity generator. The effectiveness of the center rod is varied by changes in the rod-bank position; therefore it must be calibrated for each new set of reactor power conditions that require a different rodbank setting.

The period method, used to obtain the peak reactivity variation for Test No. 1, cannot be used to evaluate reactivity in the power tests, since the power reactor seeks a power level which generates just enough reactivity in steam voids to balance the excess reactivity inserted by rod withdrawal.

Calibration was attempted by interchange of reactivity between the center rod (at its stroke limits) and the rod bank while holding the reactor power constant. The center rod reactivity worth was then determined by the hot non-boiling reactivity calibration available for the rod bank from earlier experiments. The test data were then normalized and plotted by the method described previously for Test No. 1. The curves consistently did not return to the $G$ function at high frequencies as required by the physical nature of the feedback mechanism. Additional experiments indicated that rod worth was a function of the void condition in the reactor. For this reason the curves shown in the next section were normalized by. arbitrarily requiring that they return to the $G$ function at a frequency of $25 \mathrm{radians} / \mathrm{second}$. The $\delta \mathrm{k}$ effectiveness required to place the curve on the $G$ function is given in Table II under the individual test. Preliminary calculations on the $\mathrm{H}$ function have justified this assumption.

The above process affords a void reactivity measurement which is independent of rod calibrations. The absolute gain of the zero-power reactor function, $G$, can be calculated for a frequency of 25 radians/second. The static measurement of $P_{1}$, and a measurement of $P_{1}$ at 25 radians/ second, will provide the ratio of static gain to $G$ function gain at $25 \mathrm{radians} /$ second. The static gain, determined by multiplying the calculated gain by the measured ratio, is found equal to $\mathrm{I} / \mathrm{H}_{1}$ :

$$
\begin{aligned}
& P_{1}=\frac{G}{1+G_{1}}=\left(\frac{G_{1}}{1+G_{1}}\right) \quad\left(\frac{1}{H_{1}}\right) \\
& \cong \frac{1}{H_{1}} \quad \text { for } G_{1} \gg 1 .
\end{aligned}
$$

Then:

$$
\mathrm{H}_{1}=\mathrm{P}_{1}^{-1}
$$


and $\mathrm{H}_{1}$, divided by the power in megawatts, becomes the slope of the voidreactivity vs power curve at that power. The $k$ in voids is obtained by plotting slopes for several powers at constant pressure and integrating the result.

\section{POWER TRANSFER FUNCTIONS}

The method used to normalize the data has been described in Part D of Section IV. The curve variables as plotted are defined in Section II. The test data are presented in Table II. The curves are grouped to illustrate the effect of varying a particular parameter.

\section{A. Power Output as the Variable}

The curves in Fig. 5 show the effect of increasing power. A small amount of peaking is evident at all three power levels, with the peak amplitude showing some increase with power. The characteristic rise at the low-frequency end of the curves is due, in part, to the influence of the pressure portion of the feedback loop. If pressure were constant, the curves would show less rise with decreasing frequency in the area below one radian/second, and each curve would level out to some constant value at low frequencies.

\section{B. Pressure as the Variable}

The curves in Fig. 6 show the effect of decreasing pressure. The power level in all cases is nominally 5 megawatts. Again peaking is in evidence, increasing with decreasing pressure. This could be expected since the voids are inversely related to pressure and thereby create a higher open loop gain as the pressure is lowered. Greater gain will increase peaking and produce higher peaks provided the phase remains nearly constant. Note that the $5.1 \mathrm{mw}-131.5$ psi curve of Fig. 6 nearly duplicates the $19.9 \mathrm{mw}-550$ psi curve of Fig. 5 in the resonance region. This indicates that the void conditions for higher powers may be obtained where the pressure is reduced by the ratio of power increase being. simulated.

\section{Rod-Bank Position as the Variable}

Figure 7 illustrates the effect of increasing core length by adding boron. The peaking is about the same. The decreased closed loop gain $\left(P_{1}\right)$ at low frequencies in the test without boron addition indicates the presence of more voids. These two facts suggest that the heat transfer time constants are longer in the test with boron addition (possibly because of film coefficient change). This would produce more open loop phase shift. The decrease in open loop gain, due to reduced voids, would then be offset by the additional phase lag to produce the same peaking in both tests. 

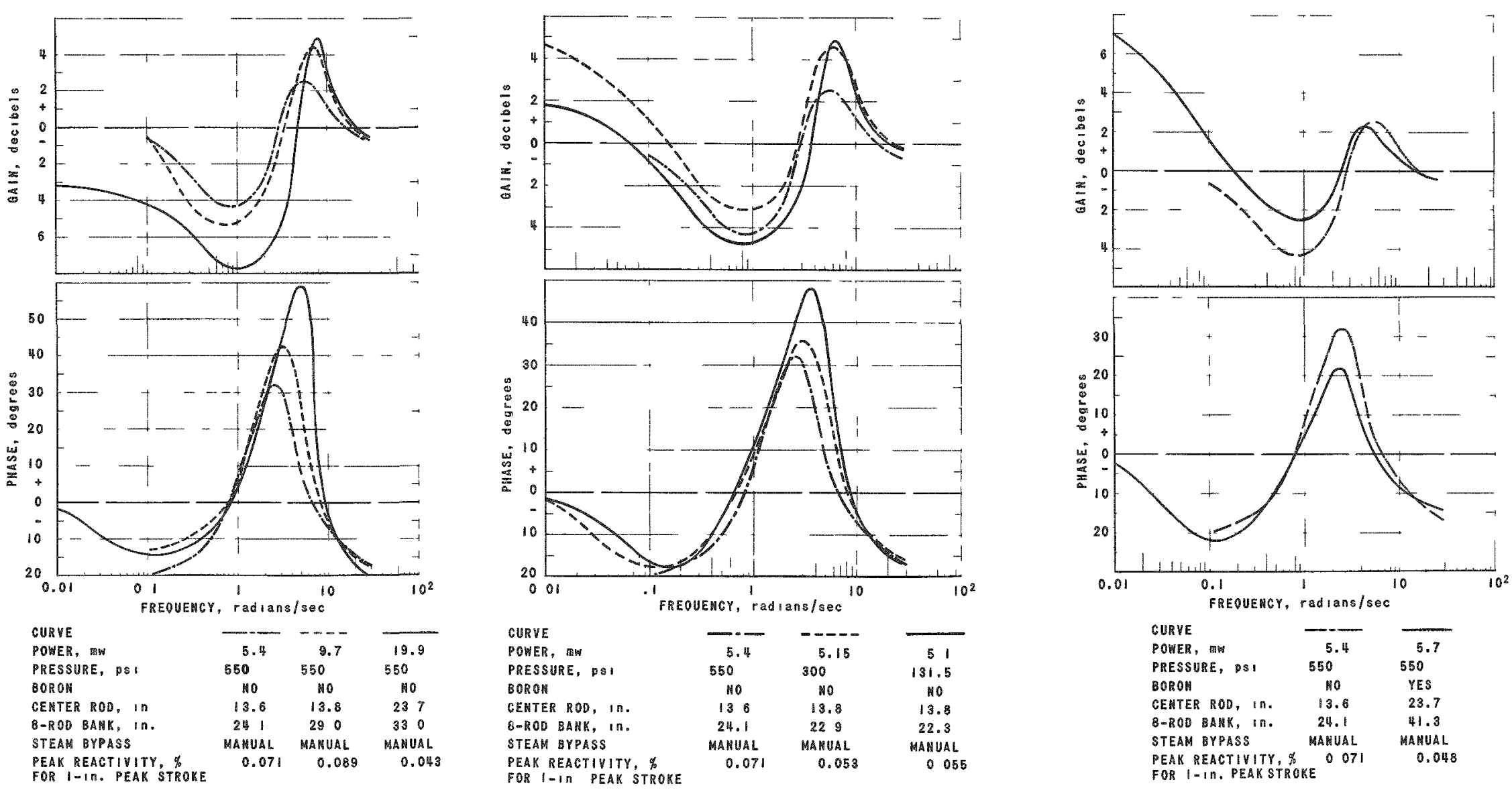

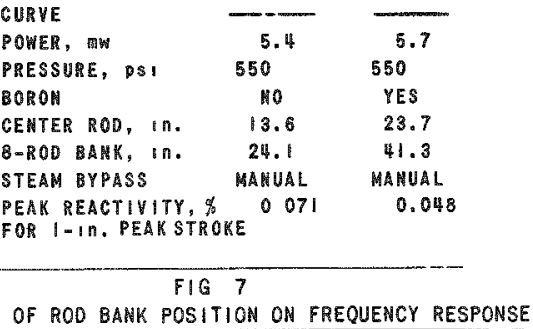

EFFECTS OF POWER ON FREQUENCY RESPONSE

EFFECTS OF PRESSURE ON FREQUENCY RESPONSE 


\section{Multiple Parameter Variation}

The composite Fig. 8 shows the effects of multiple parameter variation on frequency response. Tests No. 11 and No. 13 are of interest since they represent a rough cut at a constant-pressure test by the use of automatic steam bypass control.8 The results can be compared with Test No. 10 and the 19.9-megawatt curve of Fig. 5, respectively. The comments on constant pressure (see Part $A$, this section) as it affects the shape of the curve at low frequencies are borne out by these data.

\section{CONCLUSIONS}

The foregoing experiments demonstrate that accurate incremental frequency response data may be obtained from a boiling reactor to aid in determining the factors which contribute to its stability. The data are qualitatively in agreement with the theoretical model ${ }^{9}$ and can be analyzed to obtain quantitative agreement. Analytic solutions have been fitted to the experimental data and extrapolated to predict transfer functions and stability at higher powers with reasonable accuracy.

The feedback method for determination of reactivity in voids should prove useful, because rod calibrations are not necessary. A reactivity generator capable of static output and one high frequency output (say 50 radians/second) would give a rapid means for determination of reactivity in voids by this method.

9. S. Beckjord "Dynamic Analysis of Natural Circulation Boiling Water Power Reactors。" (To be published as ANL-5799) 

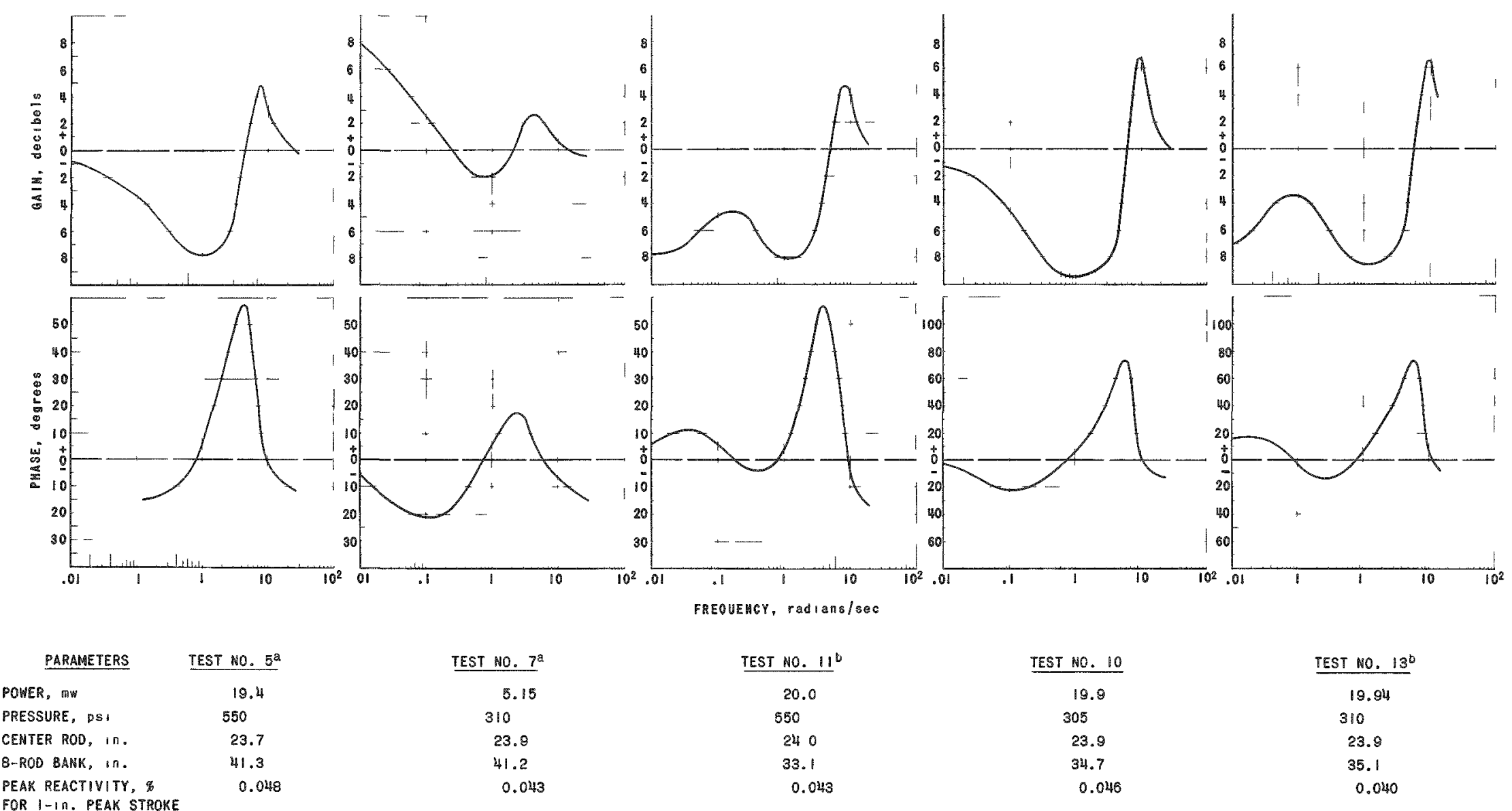

a. $\mathrm{H}_{3} \mathrm{BO}_{4}$ ADOED

b autOMATIC steam bypass

FIG. 8

EFFECTS OF MULTIPLE PARAMETER VARIATION ON FREQUENCY RESPONSE 


\section{APPENDIX A}

\section{REACTIVITY INPUT FUNCTION GENERATOR}

The reactivity generator consists of a hydraulically operated servo transmission which drives an amplitude selector or variable stroke bell crank through a gear transmission. A connecting rod coupled to the amplitude selector actuates the control rod through an intermediate control rod extension

The servo transmission (Fig. 9) consists of a variable displacement aircraft-type piston pump, which hydraulically drives a fixed displacement aircraft-type piston motor. The transmission is controlled by a solenoidoperated pilot valve which directs flow to a control cylinder to actuate the pump yoke in accordance with the solenoid input signal. The position of the yoke determines the direction and rate of output flow from the pump.

A 400-cycle feedback synchro geared to the pump yoke supplies the necessary error signal to the electronic amplifier controlling the solenoid to provide yoke position.

The reversible hydraulic motor is capable of developing a maximum speed of $2200 \mathrm{rpm}$. Pressure relief is set at 1000 psi. Solenoid-operated valves installed in the line between the pump and the motor provide declutching of the pump and instantaneous braking of the motor. In the declutched position, the pump output is directed back to the pump input.

An auxiliary vane pump driven by a $1.5-\mathrm{hp}$ electric motor supplies control pressure to the yoke control cylinder and replenishes pressure to the servo system. The pump and motor are mounted on a 20-gallon reservoir along with the necessary relief valves and gauges for regulating the pressure in the control and replenishing circuits. Control pressure is maintained at 600 psi. Replenishing pressure is regulated to 55 psi.

Test data obtained in preliminary runs of the hydraulic transmission indicated that motor output speeds between 2000 and $100 \mathrm{rpm}$ gave the best over-all response. Using these values as limits of hydraulic motor speed, an additional mechanical transmission was installed to provide the necessary speed range coverage.

The mechanical transmission, geared to the output shaft of the hydraulic motor, consists of four sets of spur gears mounted on self-aligning pillow blocks (Fig, 10). Basically the transmission reduces the motor speed by a factor of $4-2 / 3$. Three additional gear changes, each of which add a reduction factor of 5 , are required to cover the operating range of 4 to 0.0025 cycles/second. A small d-c permanent magnet generator geared to the output shaft of the motor supplies the necessary signal to a panel meter for speed and frequency indication. 

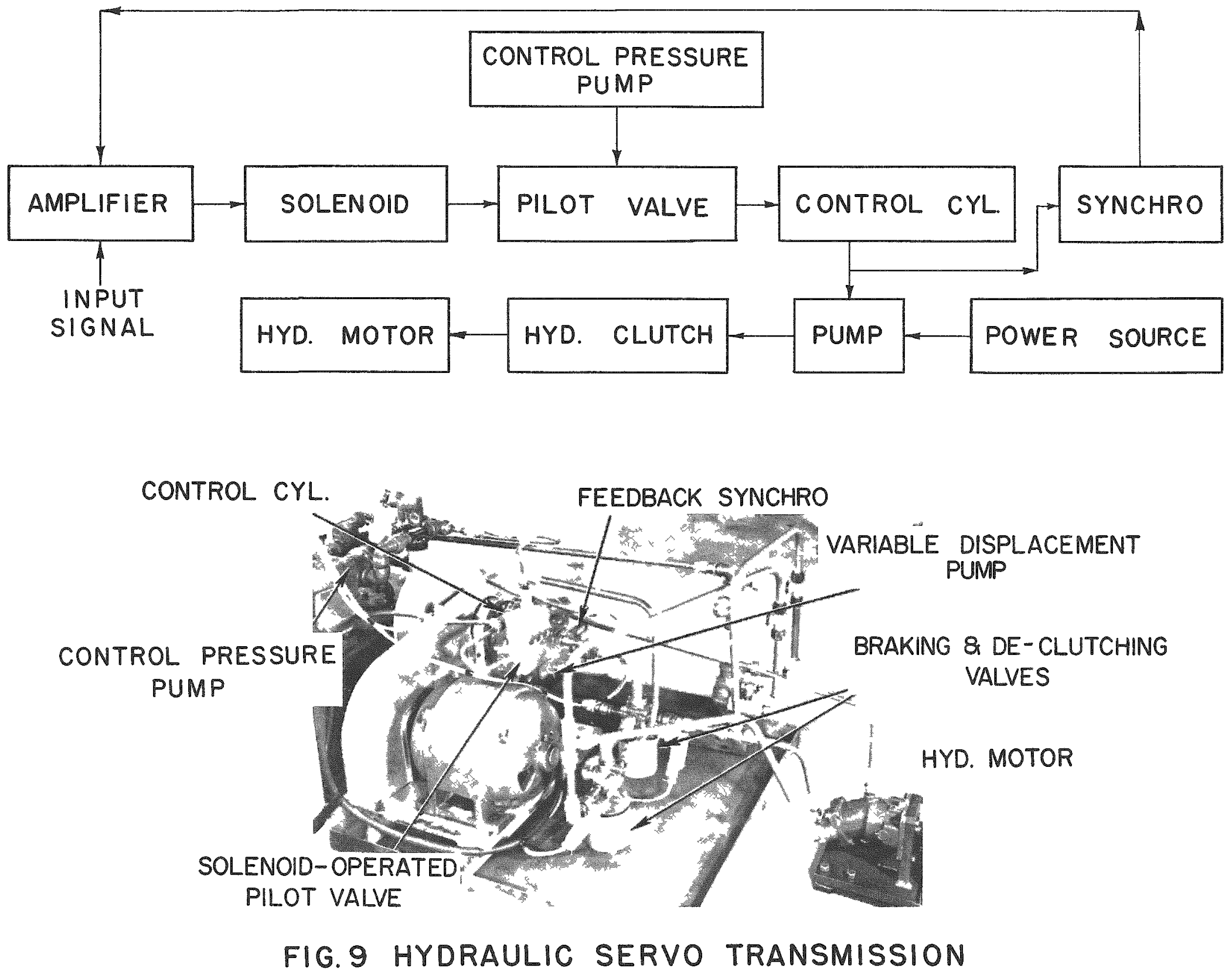


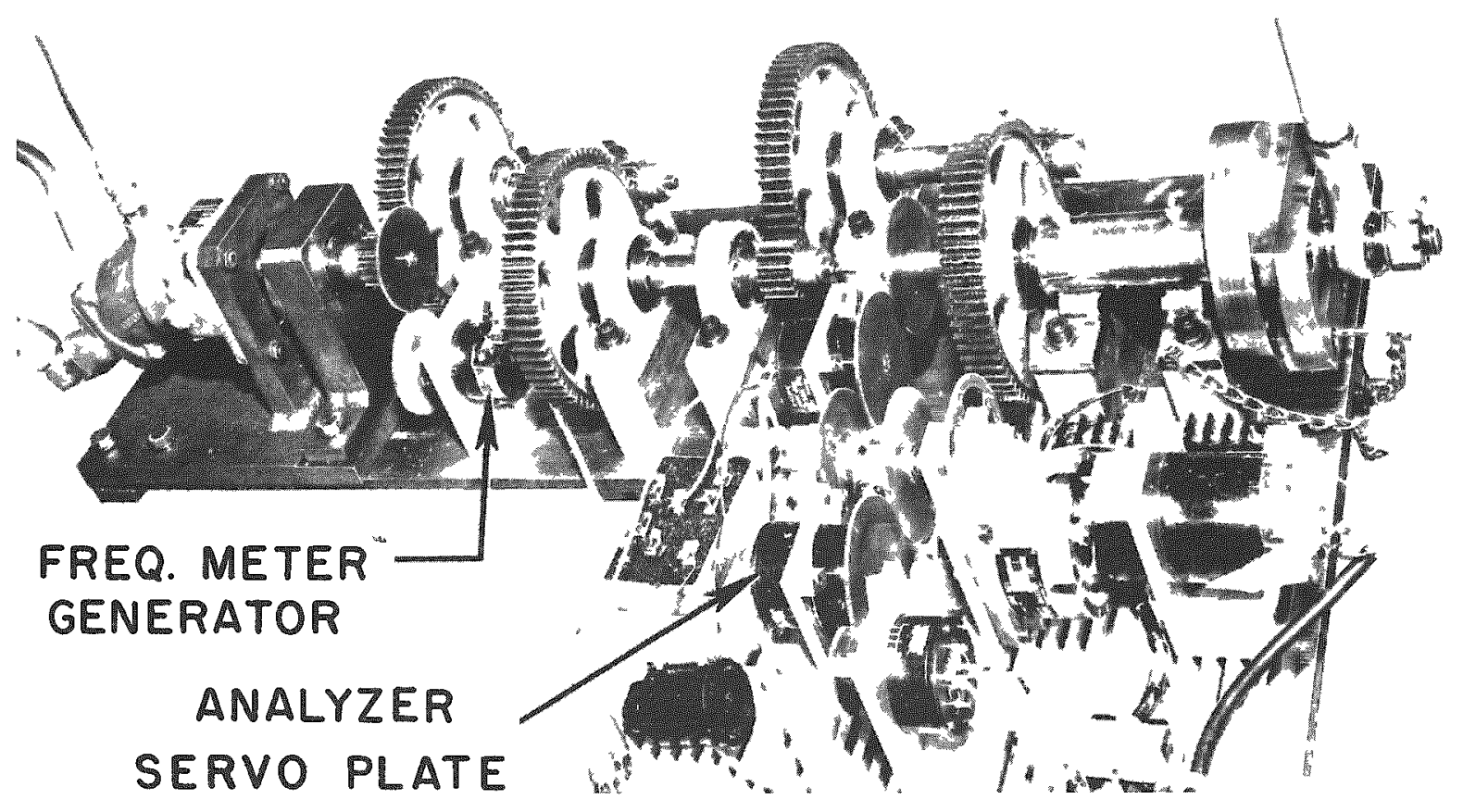

FIG. 10

\section{REACTIVITY GENERATOR GEAR TRANSMISSION}

Amplitude regulation is obtained at the output of the gear transmission by an amplitude selector. The amplitude selector (Fig. 11) consists of a threaded "T"-shaped stud which slides in an elongated slot of the drive plate. The underside of the plate and the mating surface oi the stud " $T$ " head contain linear threads (1/16-in. pitch) which lock together when tightened. Graduations on the side of the plate slot permit selection of rod amplitude to a maximum value of 4 in. peak-to-peak. The calibration is indicated in $1 / 2-i n$. peak-to-peak intervals. A locknut secures the connecting rod universal bearing to the selector stud and locks the mating threads in place.

An amplitude mean-reference hole is provided in the drive flange and in the pillow block support adjacent to the drive flange. When the two holes are aligned and the mean-reference locking pin inserted (see Fig. 10), the control rod is located at the mean position in the amplitude selector. The metal flag on the locking pin chain warns the operator that the drive shaft is pinned. Whenever the transmission is not in operation, the control rod is returned to its mean-reference position, adjusted to zero amplitude on the selector and locked in place with the mean-reference locking pin. 


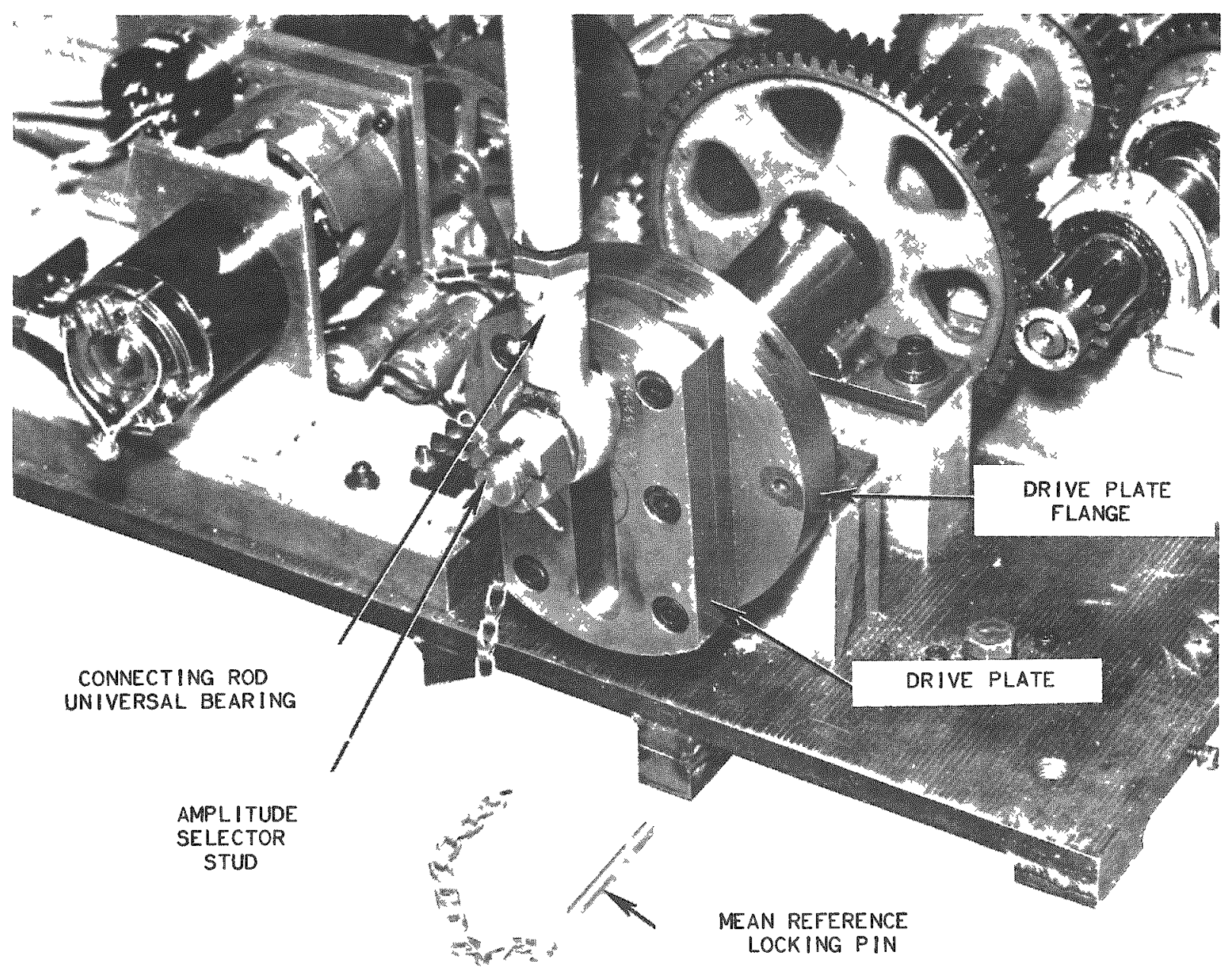

FIG. 11

REACTIVITY GENERATOR AMPLITUDE SELECTOR

As a precaution against damage to the reactor core in case of control rod binding, a shear pin is installed in the output shaft to disengage the transmission in event of excessive rod loading.

The transfer function reactivity drive was coupled to the center control rod after removal of the positioning indicator and the external dash pot from the control rod housing. A support block with a bronze guide bushing was accurately positioned and bolted to the housing base to guide and support the control rod extension during operation (Fig. 12). The extension rod was inserted through the guide bushing and connected to the 
control rod by a threaded coupling. The coupling was pinned to an external bracket to prevent movement during rod motion. The projecting end of the extension rod was coupled to the universal bearing of the connecting rod.

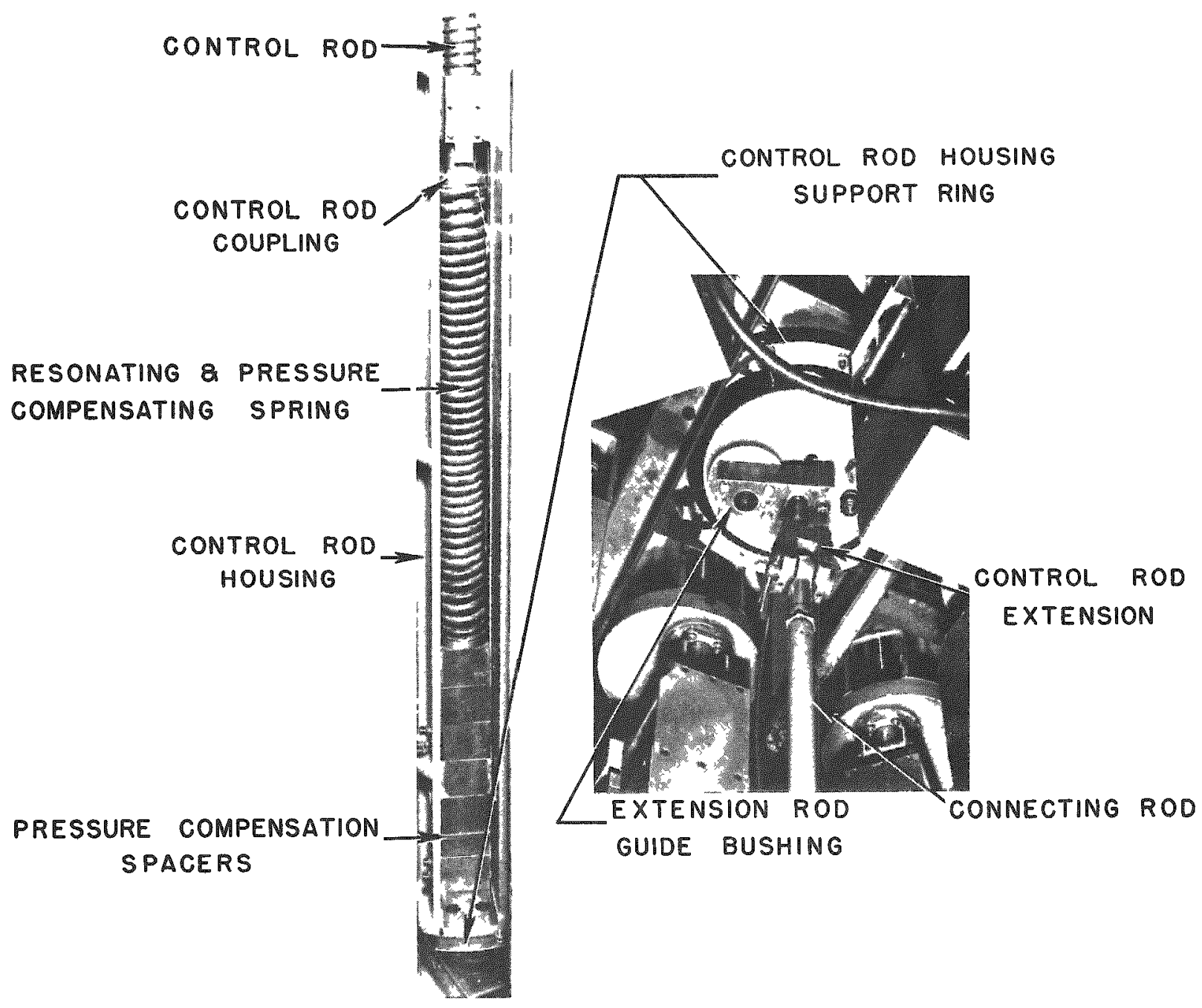

FIG. 12

TRANSFER FUNCTION REACTIVITY DRIVE

The connecting rod (Fig. 13) couples the amplitude selector to the control rod extension. Universal bearings at each end of the rod compensate for any mechanical misalignment. The vertical ribs welded on opposite sides of the rod act as stiffeners. These stiffeners are placed in the plane of rod motion to conteract inertia forces developed during highspeed operation. 


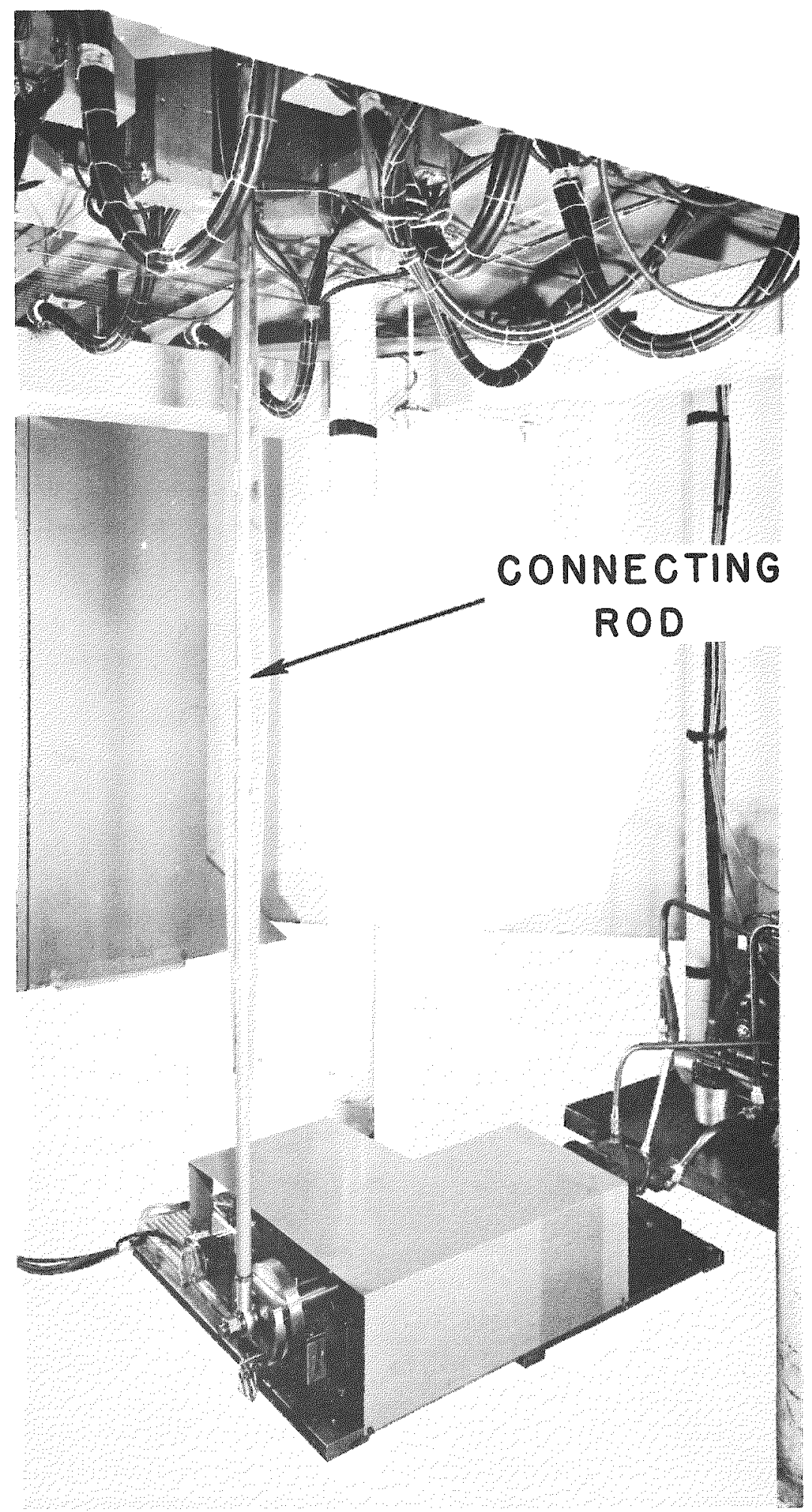

FIG. 13

REACTIVITY GENERATOR DRIVE ASSEMBLY 
Since the control-rod housing is supported only at the base of the reactor, a support structure was used to protect the housing against horizontal thrust that the reactivity drive might introduce. The structure consists of four cross nembers, rigidly fastened to the control-rod drive platform, supporting a guide ring which encircles the housing. Four set screws equally spaced in the ring retain the housing through spherical bearings. Spherical bearings are necessary to allow for axial movement under thermal stresses while still restricting horizontal motion. Figure 12 shows the support structure as viewed from below the platform.

Test procedure dictated that the control rod be oscillated about two different reference levels. The first reference level required the control rod to be $14 \mathrm{in.}$ from its "all in" position. The second level placed the control rod at 24 in. from "all in." Initial measurements were made with the control rod at its lowest position, to establish reference points so that the control rod could be accurately located throughout the test operation.

To minimize the load on the drive mechanism, a resonating and pressure-compensating spring was provided to balance out the control-rod weight and reactor pressure component (Fig. 12). Prior to each test operam tion, the control rod was statically balanced at the required reference level by the insertion or removal of pressure compensating "U"-shaped spacers located around the extension rod underneath the spring guide. At any reactor power level, the load on the reactivity generator is the reby independent of reactor pressure and proportional only to the compensating spring constant, the amplitude of motion, and the speed of operation. Three compensating springs with different constants were available to provide optimum operation at all speeds and pressure ranges.

The wave analyzer servo plate $(F i g .10)$ is geared directly to the out = put shaft to supply test data during operation. It is described in Appendix $B$ in connection with the wave analyzer. 


\section{APPENDIX B}

WAVE ANALYZER

\section{Nomenclature}

\begin{tabular}{|c|c|}
\hline$A_{1}$ & Operational amplifier; Gain, $G,>10^{5} \angle-180^{\circ}$ \\
\hline a & Setting of $R_{i n}$ \\
\hline 玉 & Voltage-producing current source $i_{0}$ \\
\hline$e_{f b}$ & Feedback voltage of correlator circuit \\
\hline$e_{g}$ & $A_{1}$ input voltage \\
\hline$e_{0}$ & $A_{1}$ output voltage \\
\hline $\mathrm{H}$ & Feedback ratio \\
\hline$i_{0}$ & Ion chamber average current \\
\hline$i_{s}$ & A current source for testing $=\frac{E+\delta k_{V}}{10^{8}}$ \\
\hline$i_{\omega}$ & Peak value of cosine component of chamber current \\
\hline$\delta k_{\mathrm{v}}$ & Voltage generated by the "zero" potentiometer \\
\hline $\mathrm{n}_{\mathrm{o}}$ & Average value of reactor flux \\
\hline$n_{\omega}$ & Peak value of cosine component of reactor flux \\
\hline $\mathrm{R}_{\text {in }}$ & $10-$ turn helipot (0.5 megohm) \\
\hline $\mathrm{R}_{1}$ & Deposited carbon resistor ( 5 megohm) \\
\hline $\mathrm{R}_{2}$ & $\begin{array}{l}50 \mathrm{~K} \text { and } 500 \mathrm{~K} \text { helipots with fixed resistors and switch- } \\
\text { ing to give } 0 \text { to } 1.5 \mathrm{megohms}\end{array}$ \\
\hline $\mathbf{R}_{3}$ & Precision resistor ( $32 \mathrm{~K})$ \\
\hline$x$ & Rotating card sine-cosine potentiometer ( $16 \mathrm{~K}$ nominal) \\
\hline $\mathrm{T}$ & Time \\
\hline$\phi$ & Phase shift angle of correlator \\
\hline$\theta$ & Phase shift of transfer function \\
\hline $1 \omega$ & First harmonic or fundamental frequency \\
\hline $2 \omega$ & Second harmonic frequency \\
\hline
\end{tabular}

The wave analyzer used for the EBWR transfer function measurements comprised an ion chamber, amplitude and phase angle correlating circuit, and a detector (Fig. 14). 


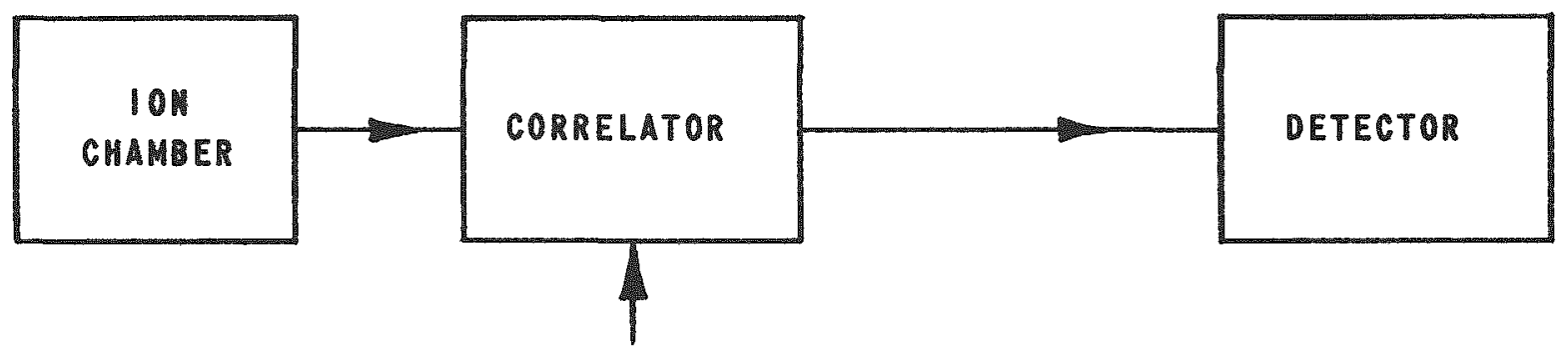

FROM REAGTIVITY

IMPUT GENERATOR

FIG. 14

BLOCK DIAGRAM OF WAVE ANALYZER

The amplitude, in terms of percentage $n_{\omega} / n_{0}$, is correlated by adjusting a feedback resistance. The phase angle is correlated by rotating a differential gear. The correlation circuit is shown schematically in Fig. 15.

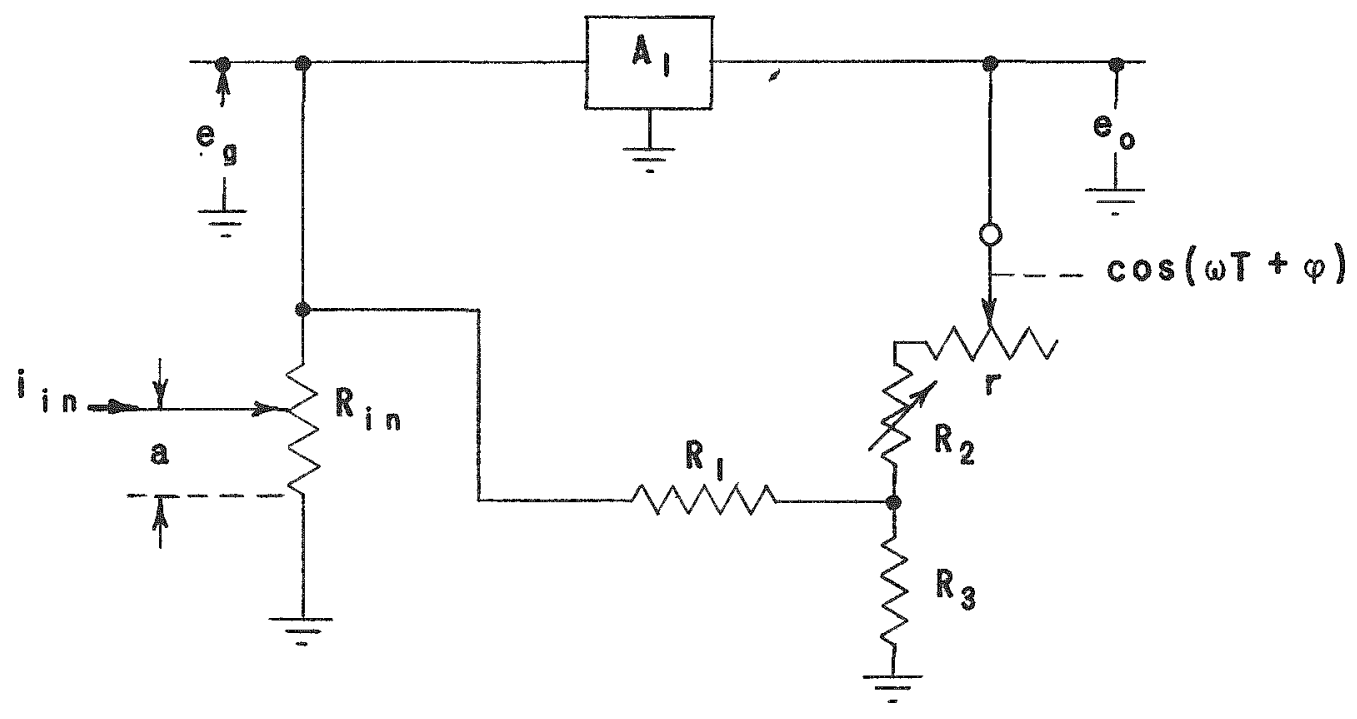

FIG. 15

CORRELATOR SCHEMATIC DIAGRAM

The ionization chamber is installed in a tangential instrument hole. It looks like a constant current source and supplies

$$
i_{i n}=i_{0}+i_{\omega} \cos (\omega T+\theta),
$$


where

$$
i_{0} \propto n_{0}
$$

and

$$
i_{\omega} \propto n_{\omega}
$$

Using Thevenin's Theorem, the input may be replaced by a voltage source $\left(i_{i n} a R_{i n}\right)$ in series with a resistor $\left(R_{i n}\right)$ :

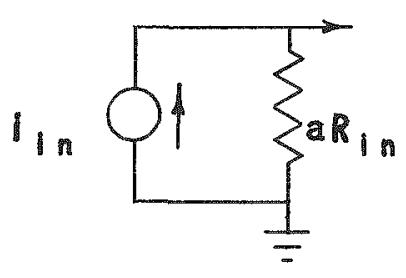

$=$

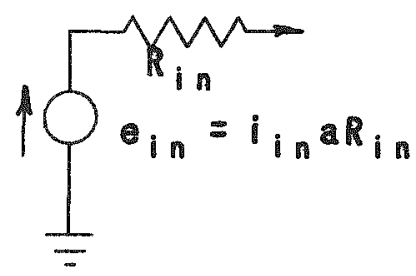

Hence, Fig. 15 can be modified as illustrated:

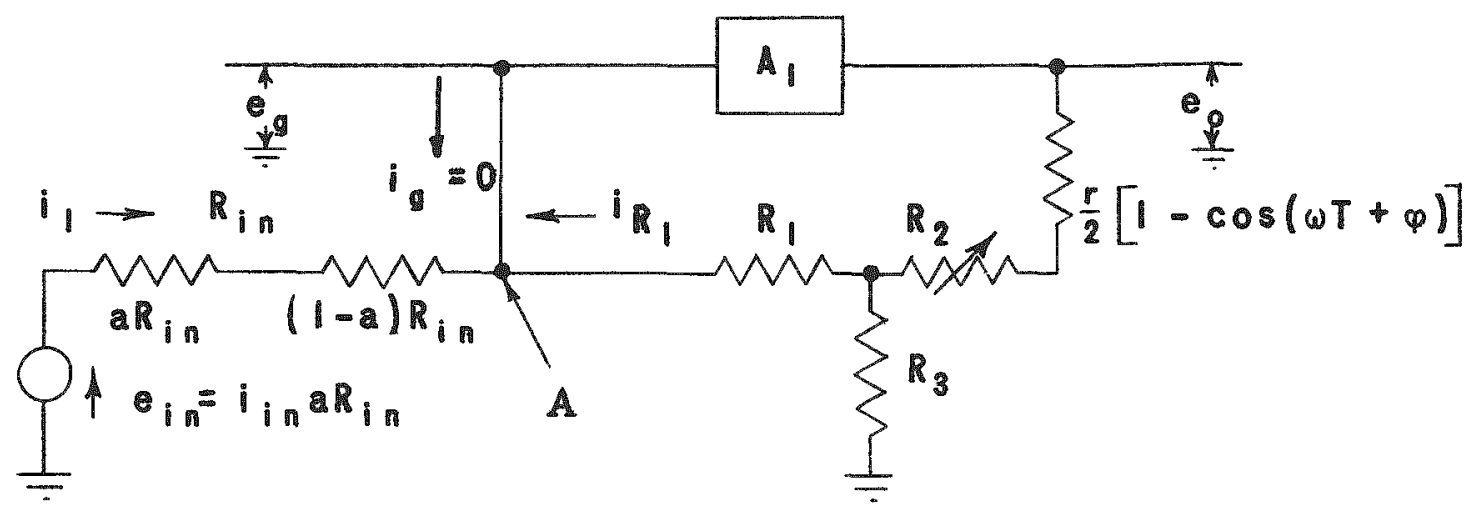

Summing the currents at junction $A$ :

$$
\begin{gathered}
i_{1}+i_{R_{I}}=-i_{g}=0 \\
i_{1}=\frac{e i n-e g}{R_{i n}} \\
\quad i_{R_{1}}=\frac{R_{3}\left\{\frac{r}{R_{2}+R_{3}+\frac{r}{2}[1-\cos (\omega T+\phi)]}\right\}-e_{g}}{R_{1}} .
\end{gathered}
$$


Note that:

$$
\begin{aligned}
& \left(R_{1}+R_{i n}\right)>>R_{3} \\
& e_{g}=-\frac{e_{0}}{G} .
\end{aligned}
$$

Therefore,

$$
\frac{e_{i n}+\frac{e_{o}}{G}}{R_{\text {in }}}+\frac{e_{o}\left\{\frac{R_{3}}{R_{2}+R_{3}+\frac{r}{2}[1-\cos (\omega T+\phi)]}\right\}+\frac{e_{o}}{G}}{R_{1}}=0
$$

or

$$
\begin{aligned}
& \frac{e_{i n}}{R_{i n}}+\frac{e_{o}}{G R_{i n}}=-\frac{e_{o} R_{3}}{R_{1}}\left\{\frac{1}{R_{2}+R_{3}+\frac{r}{2}[1-\cos (\omega T+\phi)]}\right\} \frac{e_{0}}{G R_{1}} \\
& \begin{aligned}
& \frac{e_{i n}}{R_{i n}}=-e_{0}\left\{\frac{R_{3}}{R_{1}}\left\{\frac{1}{R_{2}+R_{3}+\frac{r}{2}[1-\cos (\omega T+\phi)]}+\frac{1}{G R_{1}}+\frac{1}{G R_{i n}}\right\}\right. \\
&=\left(-e_{0}\right)\left(\frac{R_{1}+R_{i n}}{R_{1} R_{i n}}\right)\left\{\frac{R_{3} R_{i n}}{\left(R_{1}+R_{i n}\right)\left\{R_{2}+R_{3}+\frac{r}{2}[1-\cos (\omega T+\phi)]\right\}}+\frac{1}{G}\right\} \\
& \frac{1}{G}<10^{-5}<<\frac{R_{3} R_{i n}}{\left(R_{1}+R_{i n}\right)\left\{R_{2}+R_{3}+\frac{r}{2}[1-\cos (\omega T+\phi)]\right\}} .
\end{aligned}
\end{aligned}
$$

Then:

$$
\begin{aligned}
& \frac{e_{\text {in }}}{R_{\text {in }}}=\frac{-e_{0}}{R_{1}}\left\{\frac{R_{3}}{R_{2}+R_{3}+\frac{r}{2}[1-\cos (\omega T+\phi)]}\right\} \\
& e_{\text {in }}=i_{\text {in }} a R_{\text {in }} \\
& i_{\text {in }} a=-e_{0}\left\{\frac{R_{3}}{R_{1}\left\{R_{2}+R_{3}+\frac{r}{2}[1-\cos (\omega T+\phi)]\right\}}\right\}
\end{aligned}
$$




$$
\begin{aligned}
& e_{0}=\left[\frac{-i_{i n} a R_{1}}{R_{3}}\right]\left\{R_{2}+R_{3}+\frac{r}{2}[1-\cos (\omega T+\phi)]\right\} \\
& -i_{i n}=-i_{0}-i_{\omega} \cos (\omega T+\theta) .
\end{aligned}
$$

Therefore, e consists of the following terms:

$$
\begin{aligned}
& \text { d-cterm: }\left(-i_{0}\right)\left(\frac{a R_{1}}{R_{3}}\right)\left(R_{2}+R_{3}+\frac{r}{2}\right) \\
& 1 \omega \text { term: }\left[\left(-i_{0}\right)\left(\frac{a R_{1}}{R_{3}}\right)\left(-\frac{r}{2}\right)\right] \cos (\omega T+\phi) \\
& -\left[(i \omega)\left(\frac{a R_{1}}{R_{3}}\right)\left(R_{2}+R_{3}+\frac{r}{2}\right)\right] \cos (\omega T+\theta) \\
& \text { cos } \operatorname{corm}^{2} \operatorname{ter}\left(i_{\omega}\right)\left(\frac{\operatorname{arR} R_{1}}{2 R_{3}}\right)[\cos (\omega T+\theta)][\cos (\omega T+\phi)] \text {. }
\end{aligned}
$$

The detector circuit is capacitor coupled; hence, the $\mathrm{d}-\mathrm{c}$ component. can be neglected. The $1 \omega$ term can be reduced to zero by setting the coefficients equal when $\theta=\phi$. When $\theta=\phi$, the $\cos ^{2}$ term resolves to a $d-c$ and a $2 \omega$ term. Note that the value of "a" does not affect the balance conditions, and that $\mathbb{R}_{1} / \mathbb{R}_{3}$ is a constant.

When $\theta=\phi$, the $1 \omega$ term is:

$$
\frac{a R_{1}}{R_{3}} \cos (\omega T+\phi)\left[i_{0} \frac{x}{2}-i_{\omega}\left(R_{2}+R_{3}+\frac{r}{2}\right)\right]
$$

For balance,

$$
\begin{aligned}
& i_{0} \frac{r}{2}=i_{\omega}\left(R_{2}+R_{3}+\frac{r}{2}\right) \\
& \frac{i_{\omega}}{i_{0}}=\frac{r}{2\left(R_{2}+R_{3}+\frac{r}{2}\right)}
\end{aligned}
$$

Figure 16 is a plot of $i_{\omega} / i_{0}$ versus $R_{2}$. It was necessary to use two values for $r$ in computing this curve. The characteristic of the cosine potentiometer was found to be:

$$
7.937 \mathrm{~K}-6.922 \mathrm{~K}(\cos \omega \mathrm{T})
$$


instead of

$8 K(1-\cos \omega T)$

therefore, $r$ in the numerator equals

(2) $(6.922 \mathrm{~K})=13.844 \mathrm{~K}$

and $x$ in the denominator equals

(2) $(7.937 \mathrm{~K})=15.874 \mathrm{~K}$.

$\frac{i \omega}{i_{0}}=\frac{6.922 K}{R_{2}+32 K+7.937 K}=\frac{6.922 K}{R_{2}+39.937 K}$.

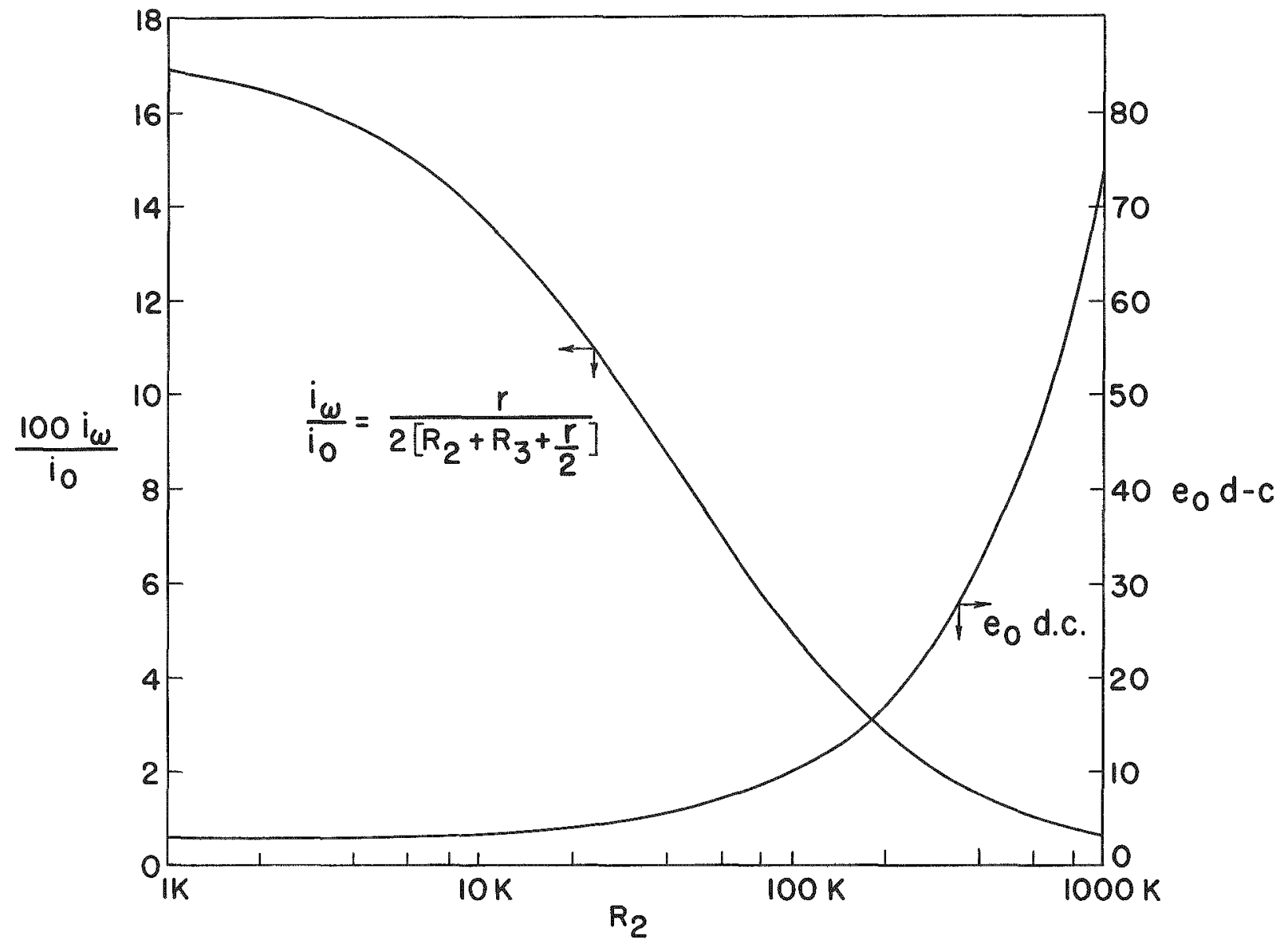

FIG. 16

CORRELATOR CALIBRATION 
It should be noted that $e_{0}$ at balance is also a measure of $i_{\omega} / i_{O}$. However, its accuracy is poor at large values of $i_{\omega} / i_{O}$.

The $\cos ^{2}$ term can be written as

$i_{\omega} \frac{\operatorname{arR} R_{1}}{4 R_{3}}[\cos (2 \omega T+\theta+\phi)+\cos (\theta-\phi)]$,

which shows the presence of a 20 component whose amplitude is a function of $i_{\omega}$ and " $a$ ". The effects of the $2 \omega$ term can be neglected provided $i \omega$ is maintained small compared to $i_{0}$. The $2 \omega$ term is fixed in relation to the $1 \omega$ term when at balance, and the magnitude is a function of i $\omega$ after "a" has been set; therefore, the $2 \omega$ term could be bucked out rather simply.

A schematic diagram of the detector is shown in Fig. 17. The $2 w$ balancing circuit is shown installed between $e_{0}$ and the filter input. Actually, the circuit was not used because too much time was required to balance it.

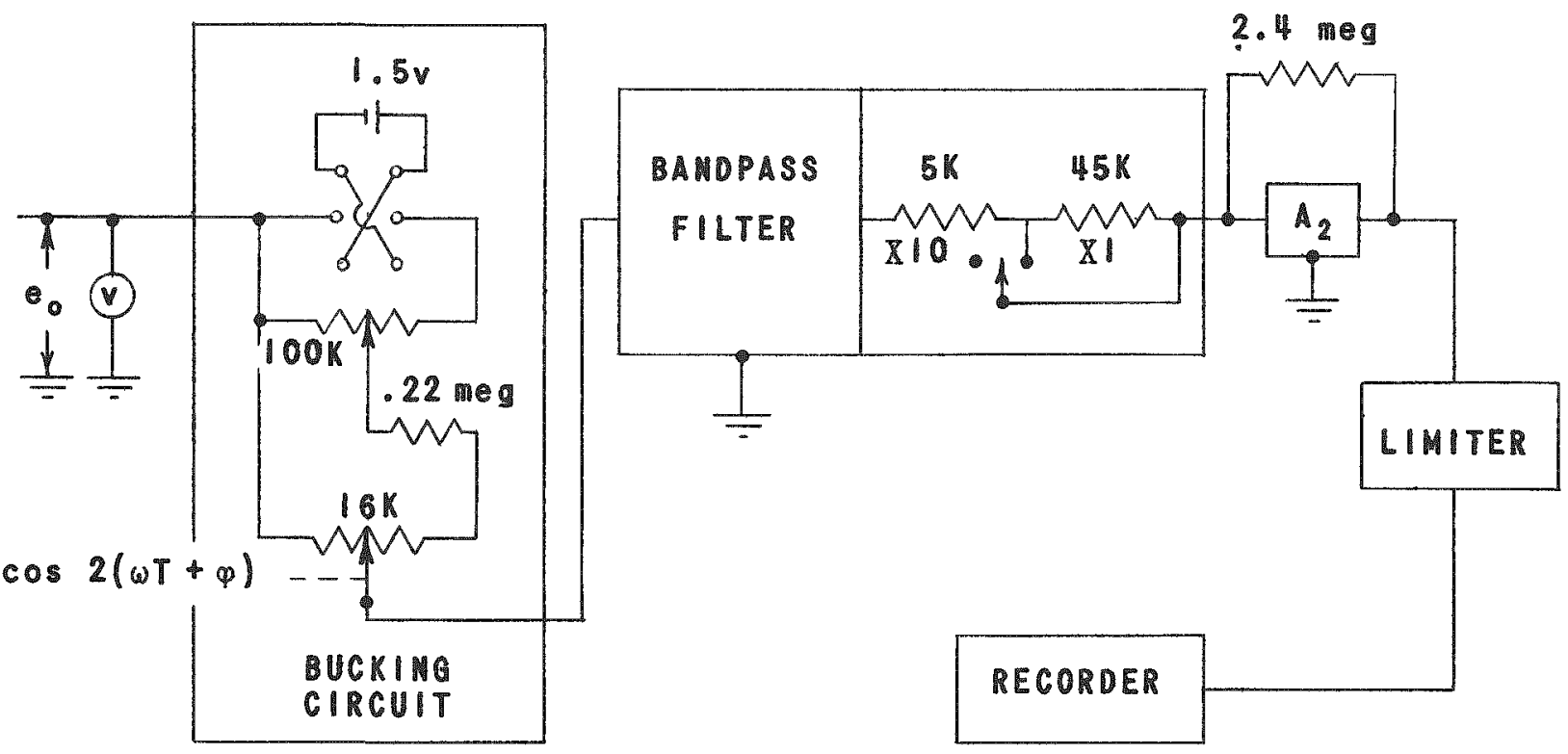

FIG. 17

DETECTOR SCHEMATIC DIAGRAM

The bandpass filter is an important detector element because it drastically reduces the boiling noise in the signal, thereby permitting satisfactory balances with signal-to-noise ratios as low as $1: 1$. Its attenuation slopes are 80 decibels/decade, and the cut-off frequencies were set 
0.707 and 1.41 times the frequency being measured. The output impedance was modified so that it was possible to attenuate the gain of the feedback amplifier, $A_{2}$, by a factor of 10 while obtaining a rough balance. $A_{2}$ is an operational amplifieridentical to $A_{1}$. The over-all gain of the detector is approximately

$$
\frac{(2.3)\left(10^{6}\right)}{(5.1)\left(10^{3}\right)}=500
$$

or

$$
\frac{(2.4)\left(10^{6}\right)}{(5.2)\left(10^{4}\right)}=50
$$

The limiter is biased diode circuit which limits the voltage into the recorder to prevent damage to the pen.

The sensitivity of the recordex is 80 volts, peak-to-peak. Using the gain values of the filter and the feedback amplifier, the full-scale sensitivity, in terms of $e_{0}$, is

$$
\begin{aligned}
& \frac{80 \text { volts }(P-P)}{50}=1.6 \text { volts }(P-P) \text { or } 0.8 \text { volt (peak) on } X 10 \text { attenuator } \\
& \frac{80 \text { volts }(P-P)}{500}=0.16 \text { volt }(P-P) \text { or } 0.08 \text { volt (peak) on } X 1 \text { attenuator. }
\end{aligned}
$$

The $d-c$ value of eo was set to 75 volts with $R_{2}=1$ Meg by adjusting "a" with the reactivity generator at mid-position. If the $1 \omega$ potentiometer were to be stopped after obtaining a balance with the above value of $R_{2}$, the peak unbalanced signal would be approximately 0.5 volt. Since the fullscale sensitivity on $\mathrm{Xl}$ is 0.08 volt (peak), full-scale deflection of the recorder is

$$
\frac{(100)(0.08)}{0.5}=16 \% \text { amplitude unbalance. }
$$

Depending on the frequency, signal-to-noise ratio, and the operator's skill, balances were obtained with residual null voltages as small as 0.2 full scale or $3 \%$, including the $2 \omega$ signal. In general, the measurement accuracy is about $\pm 5 \%$ in amplitude and \pm 2 degrees in phase.

The servo plate (Fig. 18) is mounted on the reactivity generator ground plate. The "zero" potentiometer is geared to the reactivity generator to produce an electrical output proportional to the reactivity input. The $1 \omega$ potentiometer is geared in a similar manner, but includes a 
differential so that it can be made to lead or lag the reactivity generator by the phase angle, $\phi$. A selsyn is used to drive the differential through gearing so that 360 -degree rotation of the dial from which $\phi$ is read (see Fig. 19) will also rotate the 10 potentiometer through 360 degrees. The $2 \omega$ potentiometer is coupled through a differential and gear train to the $1 \omega$ potentiometer so that it rotates at twice the speed of the $1 \omega$ potentiometer.

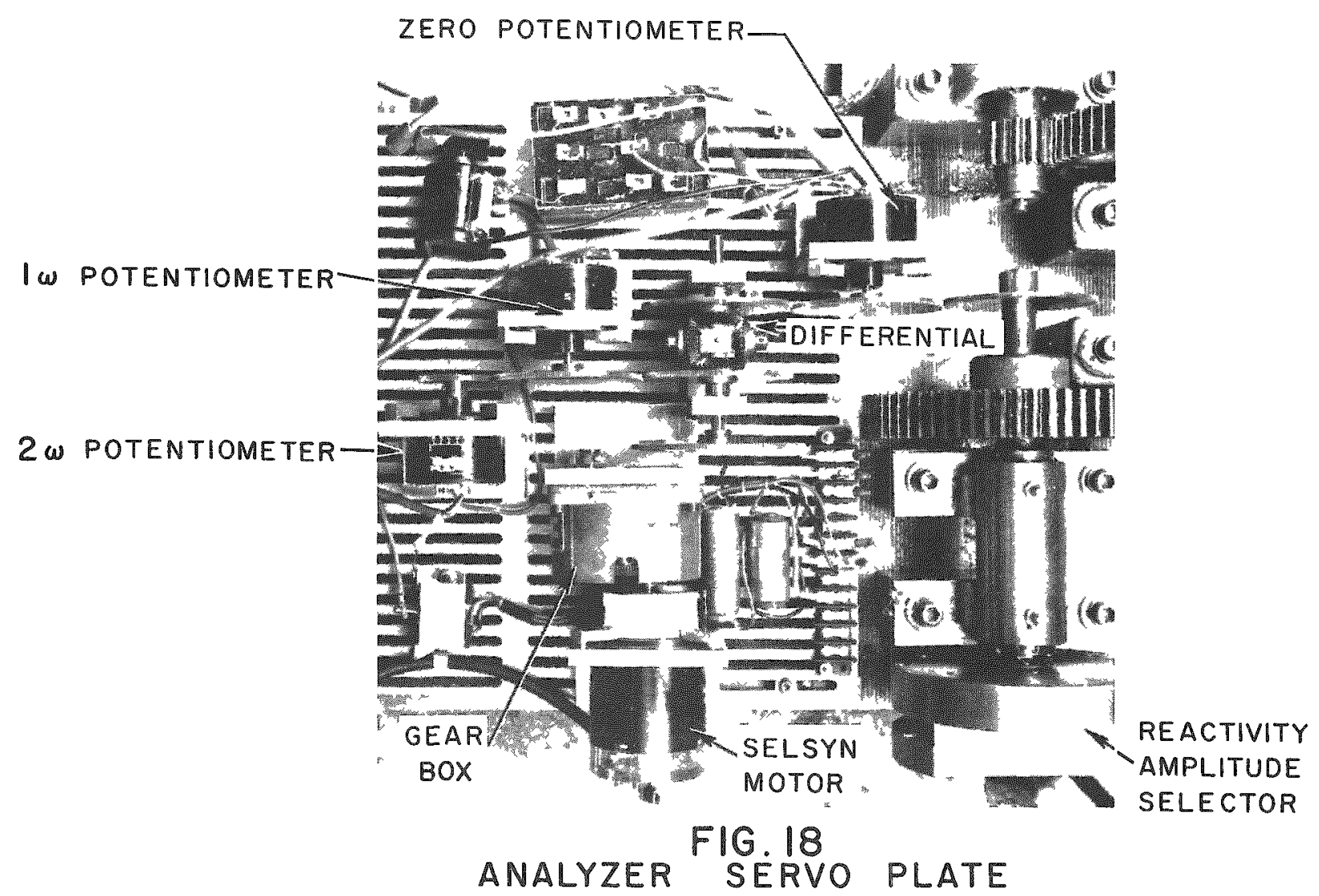

The "zero" and $1 \omega$ potentiometers are set in phase with the reactivity generator by rotating their housings while the generator is pinned in the mid-position, and with the phase dial of the selsyn-operated differential set at zero degrees.

The mid-position of the potentiometers is found by checking for minimum resistance between the fixed contact in use and the contact diametrically opposite. This method results in a 180-degree ambiguity which can be resolved by use of the test current source illustrated. With the reactivity generator amplitude set at zero, the mechanism is driven in the direction (from the mid-point position) which increases the "zero" potentiometer signal $\left(\delta \mathrm{k}_{\mathrm{v}}\right)$. 


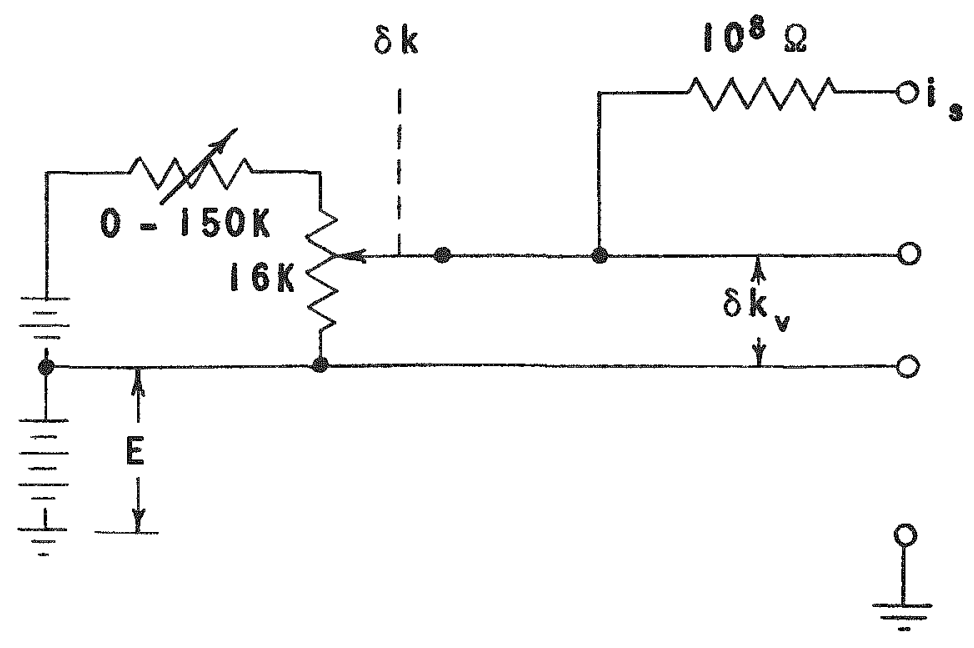

A balance can be made by substituting the testing current (is) for the ion chamber current, and by running the generator at a suitable speed $(0.2 \mathrm{rps})$. This will resolve the 180 -degree ambiguity of the 10 potentiometer and permit the correction of any small error in the zero-phase setting. The values $\delta \mathrm{k}_{\mathrm{V}}$ and $\mathrm{E}$ can be used to check the accuracy of the measured $i_{\omega} / i_{0}$. (Under the ideal conditions of this test, measurements have been made to better than $\pm 0.5 \%$ in amplitude and \pm 0.5 degree in phase.)

Figure 19 shows the Wave Analyzer and the reactivity input function controls. The reactivity frequency controls include a 400 -cycle carrier amplifier and synchronous detector driving the transmission servo valve. The loop is completed by a synchro transformer which is connected to the transmission yoke and transmits a feedback signal to the amplifier. The frequency meter registers the voltage of a $d-c$ generator coupled to the hydraulic motor.

The bandpass filter response is limited to 0.02 cycle/second; therefore, the analyzer was not used below this frequency. Instead, a six-channel recorder was used to register data from 0.04 cps down to $0.0025 \mathrm{cps}$. The six channels were:

(1) $\delta \mathrm{k}_{\mathrm{V}} \quad$ Used as the reactivity input reference.

(2) $i_{n v}$ Expanded suppressed-zero current direct from an ion chamber.

or

(3) inv Expanded suppressed-zero current from a micromicroammeter fed by an ion chamber.

(4) P Reactor Pressure

(5) Ffw Feed-water flow

(6) $\mathrm{F}_{\mathrm{s}}$ Steam flow 


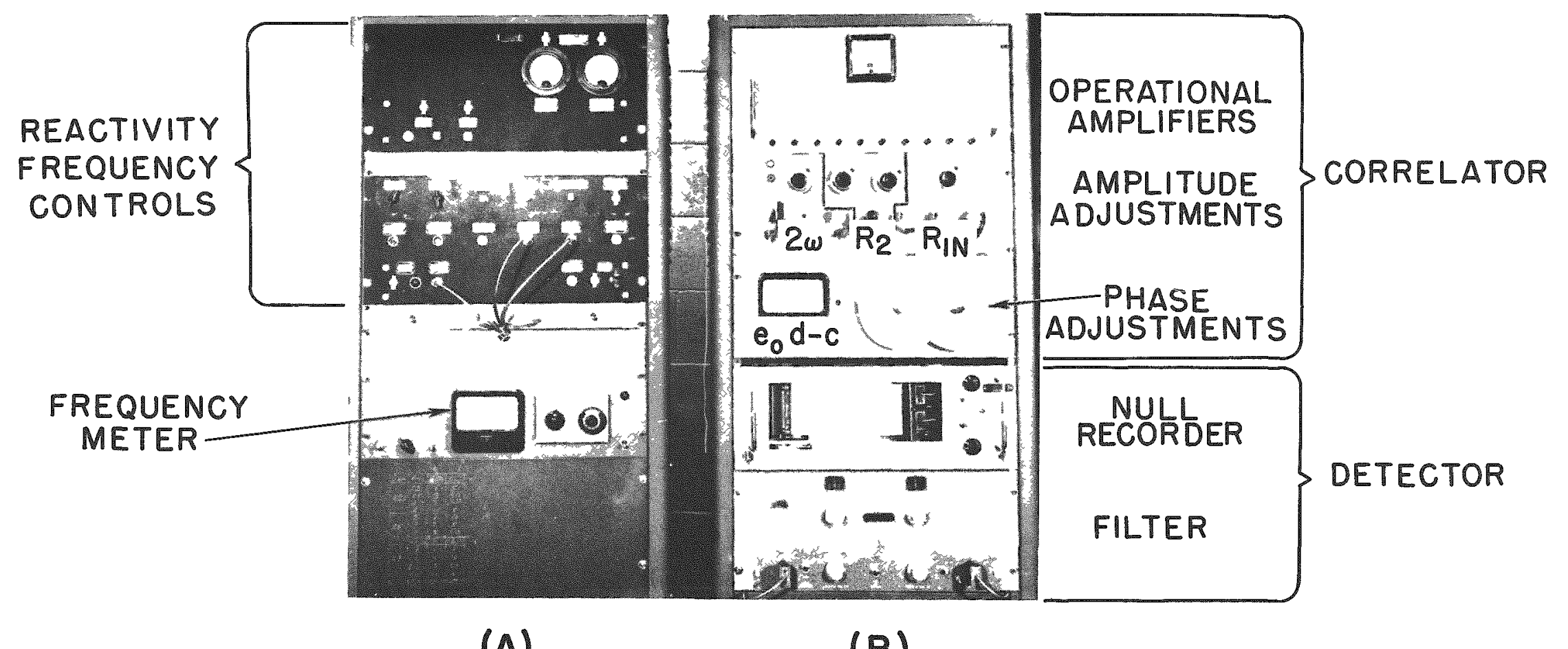

FIG. 19

(A) INPUT FUNCTION FREQUENCY CONTROLLER AND (B) WAVE ANALYZER 
With the 6-channel recorder in operation, $E$ is removed and $\delta \mathrm{k}_{\mathrm{v}}$ is applied to one of the channels. The data from channels (1), (2), and (3) were analyzed to obtain $\left|n_{\omega} / n_{0}\right| \angle \phi$.

The data from the remaining channels were used chiefly to observe system trends.

The sensitivity of the analyzer was increased for the zero-power test since the flux was low. The input circuit was modified to include a high input resistance.

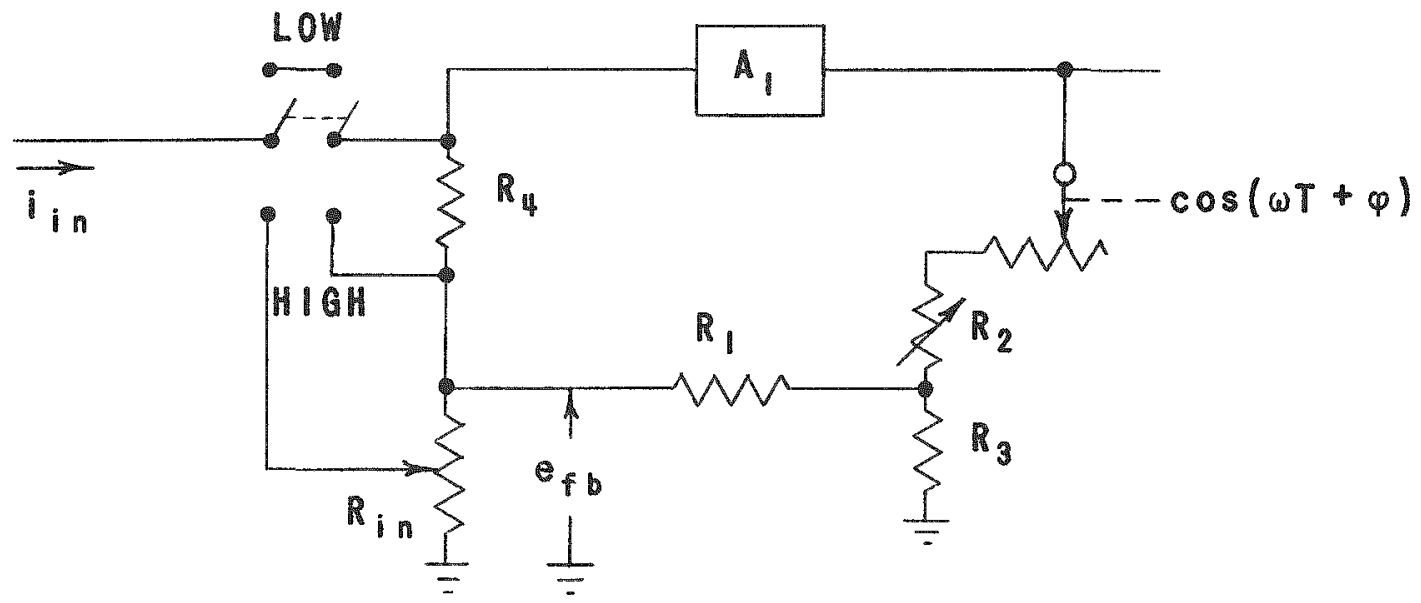

With reference to the illustration,

$$
\begin{aligned}
& e_{f b}=e_{o}\left[\left(\frac{R_{i n}}{R_{1}+R_{i n}}\right)\left(\frac{R_{3}}{R_{2}+R_{3}+\frac{r}{2}[1-\cos (\omega T+\phi)]}\right)\right]=e_{0} H_{;} R_{3}<<R_{1}+R_{i n} \\
& e_{g}=e_{f b}+i_{i n} R_{4}=-\frac{e_{0}}{G} ; \frac{R_{i n}<<R_{1}}{G} \\
& e_{o} H+\frac{e_{0}}{G}=-i_{i n} R_{4} \\
& e_{o}\left(\frac{G H+1}{G}\right)=-i_{i n} R_{4} \\
& e_{0}=-i_{i n} R_{4}\left(\frac{G H}{1+G H}\right)\left(\frac{1}{H}\right) \approx-\frac{i_{i n} R_{4}}{H} ; G H>>1 \\
& \frac{1}{H}=\left(\frac{R_{1}+R_{i n}}{R_{i n}}\right)\left(\frac{R_{2}+R_{3}+\frac{r}{2}[1-\cos (\omega T+\phi)]}{R_{3}}\right) .
\end{aligned}
$$

This is the same form as was obtained for the high-current derivation; hence the same balance conditions exist, and the only change is an increase in sensitivity. 


\section{APPENDIX C}

\section{STEAM INSTRUMENTATION}

Flow Measurement

Practical steam flow measurements are based on the pressure differential across a fixed orifice in the steam line. The mass flow is determined by extracting the square root of this differential pressure and multiplying by the suitable constant. It is apparent that the relation is approximately linear for sufficiently small flow variations about an average operating point. Differential pressure is registered by displacement of a spring-bellows device. The displacement is conveniently measured by an electro-mechanical transducer, such as a linear differential transformer. A variety of complete units for flow recording are commercially available, but none could be found to meet the time response and resolution requirements, and the test time schedule. The alternative was to purchase a flow transducer (encased bellows as sembly and differential transformer) and to add a specially designed electronic amplifier to drive the recorder.

The undamped natural frequency of a mechanical mass system is known to be

$$
f_{M}=\frac{1}{2 \pi}\left(\frac{K}{M}\right)^{1 / 2} \text { cycles/second }
$$

where $\mathbb{K}$ and $\mathbf{M}$ are, respectively, the spring constant and mass in appropriate units. In the instance of the flow meter, apparent values of mass and spring constant must be used to calculate the resonant frequency. The apparent values are the actual values corrected by the electromechanical coupling effects, and by the effects of the water mass in the pipe connecting the flow meter to the measuring point. The water mass rapidly lowers frequency response as the pipe length increases; therefore, the flow meters were placed as close as possible to the flow nozzles.

The flow-meter transducer selected (Fig. 20) contains a bellows which saturates at a pressure of 100 in. of water. Its natural frequency with no connecting lines was 13 cycles/second. An amplifier designed for use with the flow meter is shown schematically in Fig. 21. A highgain, capacity-coupled feedback amplifier amplifies the differential transformer signal and converts it to $d-c$ by means of a chopper-type demodulator. The demodulator is followed by an operational amplifier (direct-coupled) to give a low output impedance. The circuit is similar to a self-balancing potentiometer with motor removed and the balancing core hand-operated by a micrometer, as shown in Fig. 22. The amplifier 


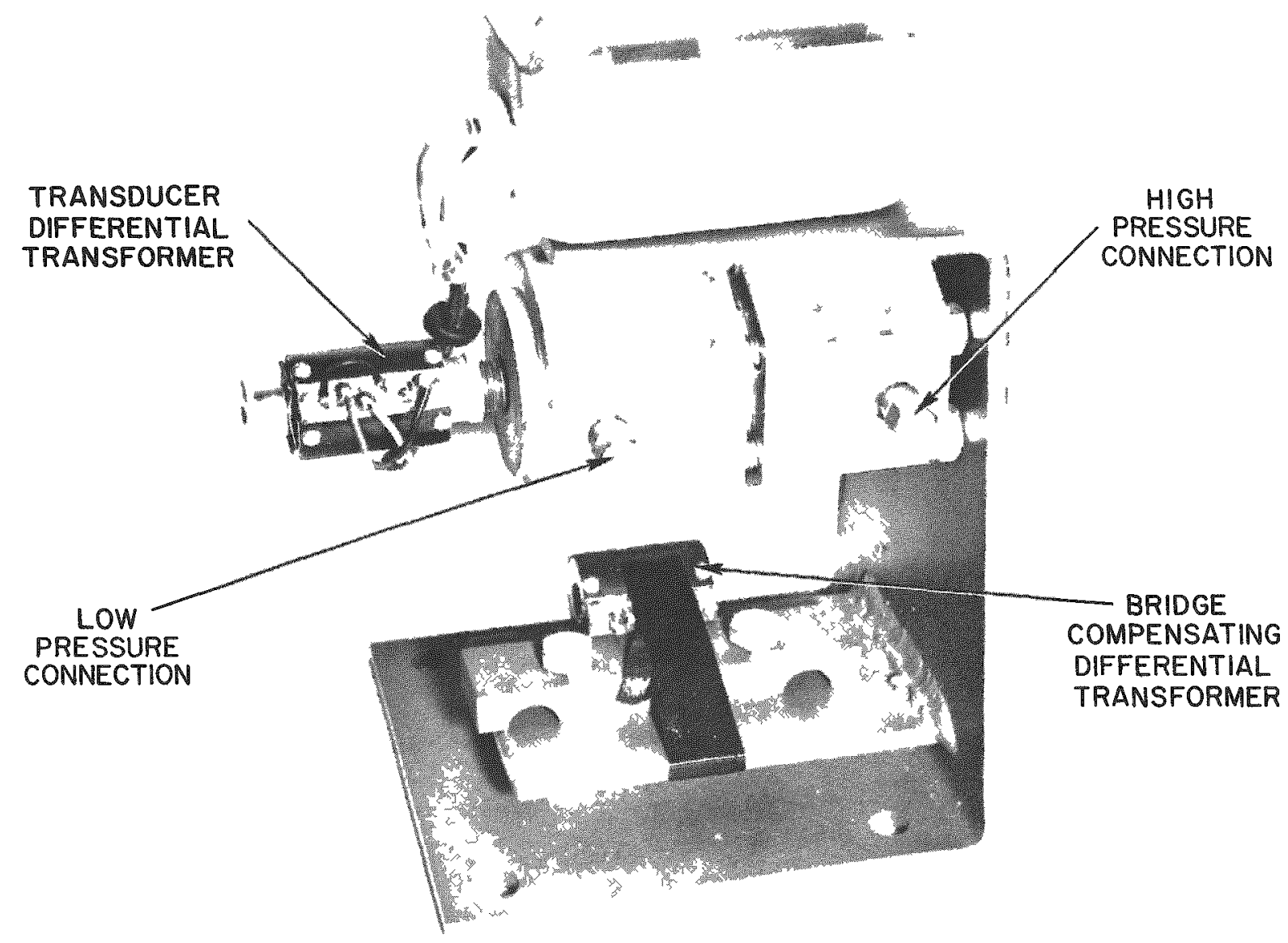

FIG. 20

FLOWMETER TRANSDUCER

output is thus proportional to incremental changes in flow around a set point. The open loop gain of the carrier amplifier is about 13,000, and the maximum closed loop gain is 1000 . The frequency response is shown in F1g. 23.

Over-all amplifier phase shift is given in Fig. 24. Figure 25 shows the measured natural frequency of the transducer for various connecting pipe lengths. The phase shift of the instrument system (Fig. 26) was obtained for the connection used at the steam flow points by adding to the curve of Fig. 24 the calculated phase shift for the mechanical system with damping set for a peak over-shoot of 1.4. The damping is obtained by partially closing one of the isolating valves to the transducer. In spite of considerable effort to obtain a high bandwidth, the plot in Fig. 6 indicates that the phase lag in the system is appreciable at $1 / 2$ cycle/second. The maximum sensitivity of the instrument is 6 volts/inch of water differential pressure. A plot of differential pressure vs flow for the EBWR nozzles is given in Fig. 27. 
DIFFERENTIAL

TRANS. CONHECTION

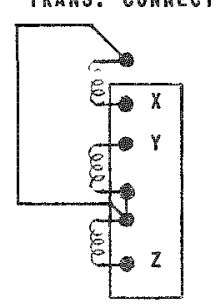

N
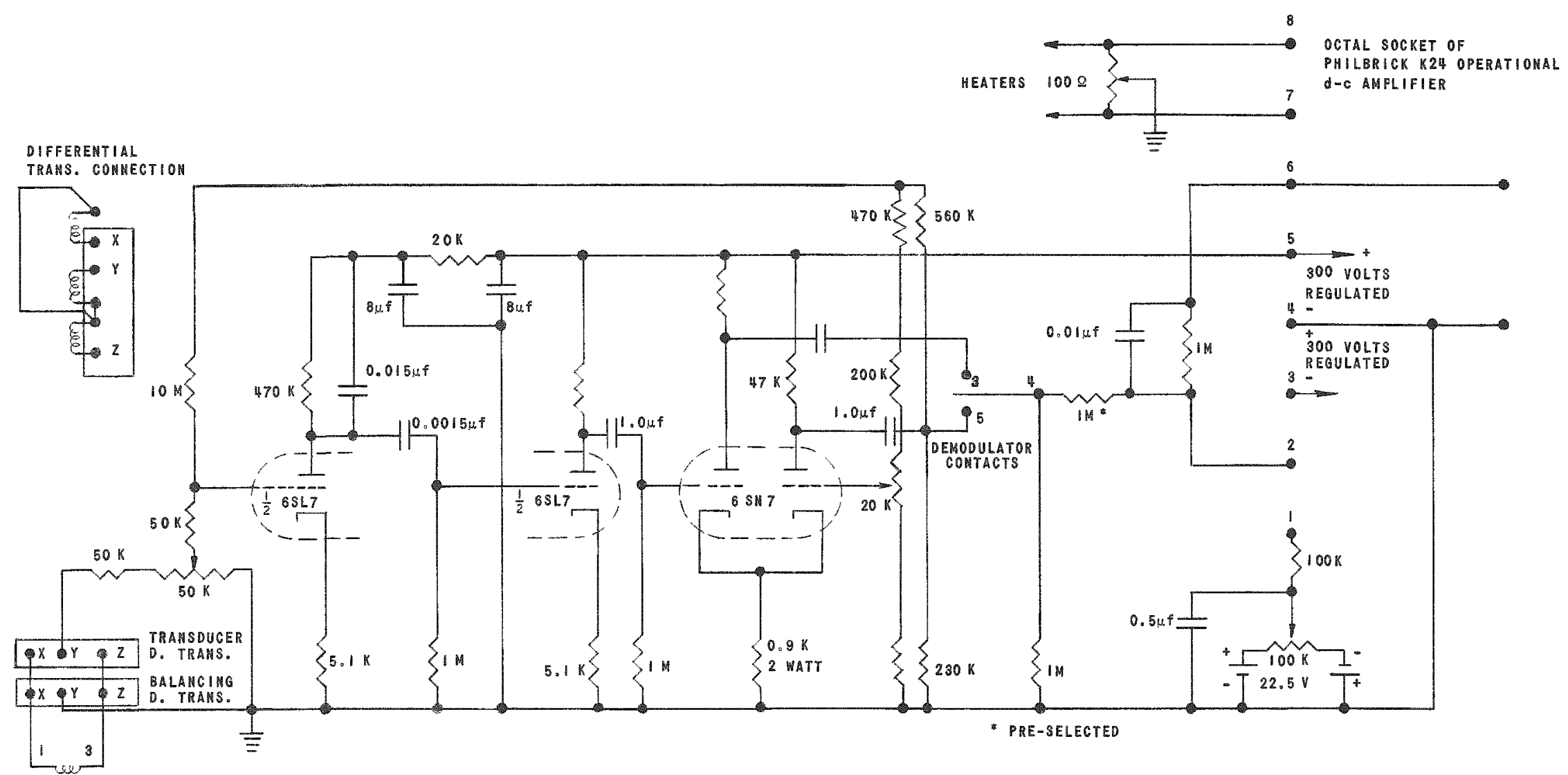

CHIGAgO STAMDARD

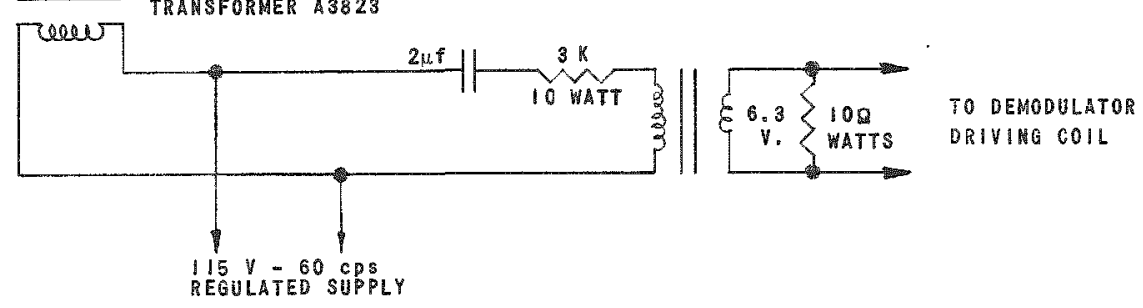




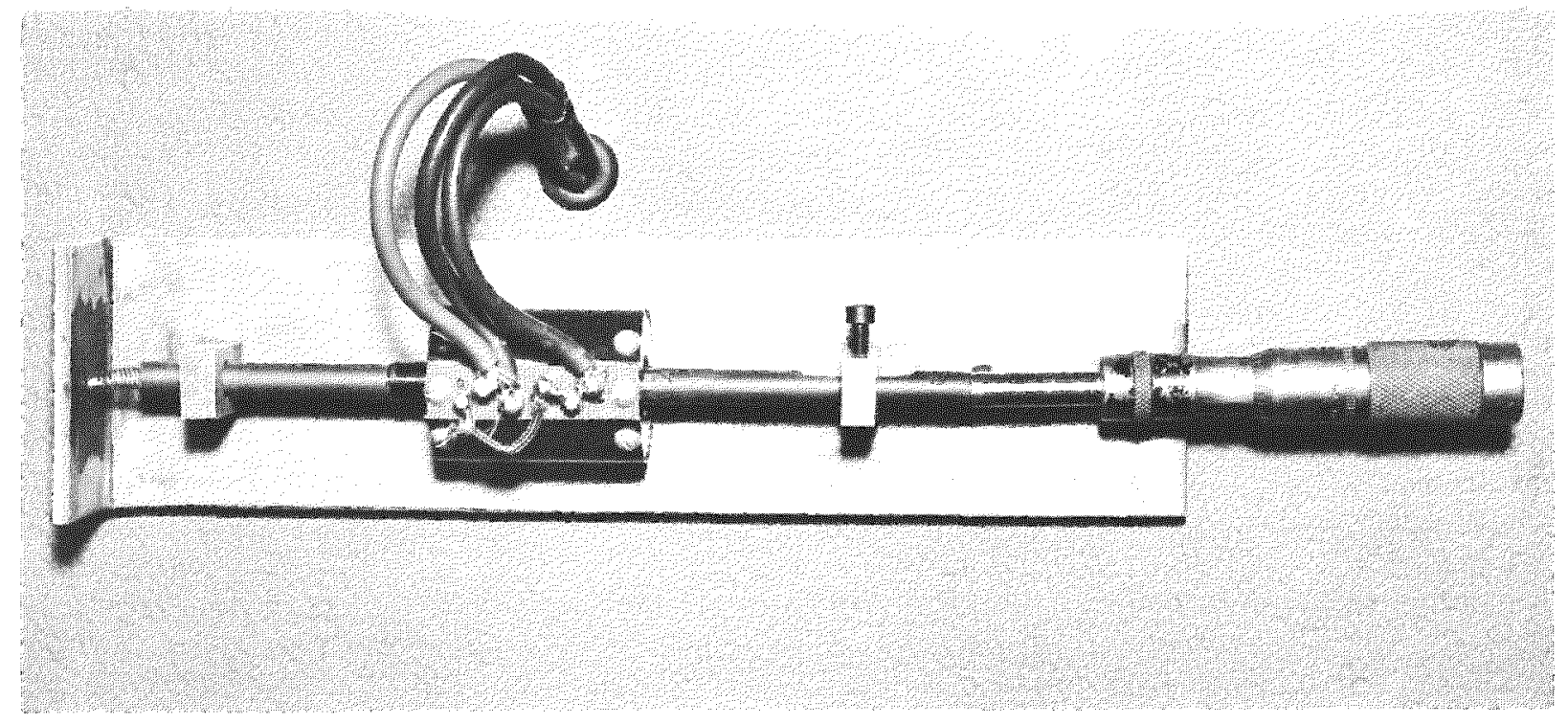

FIG. 22

MICROMETER-OPERATED REBALANCING

DIFFERENTIAL TRANSFORMER

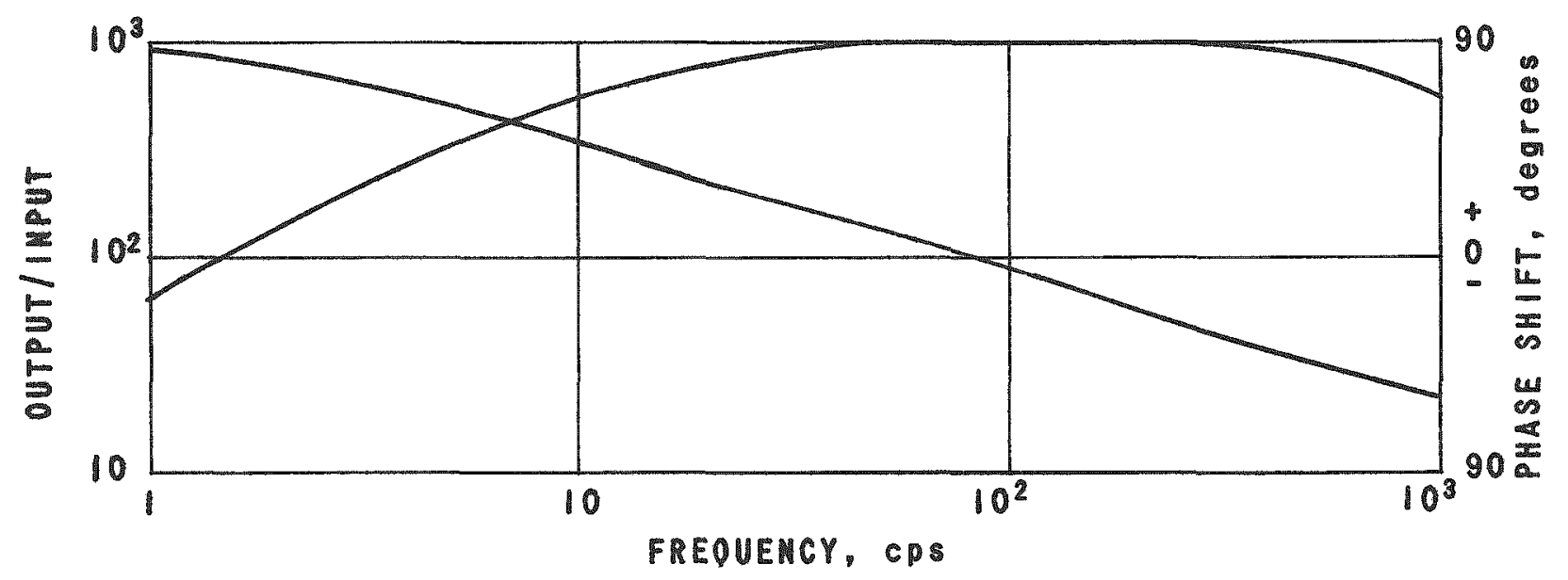

FIG. 23

FREQUENCY RESPONSE OF CARRIER AMPLIFIER 


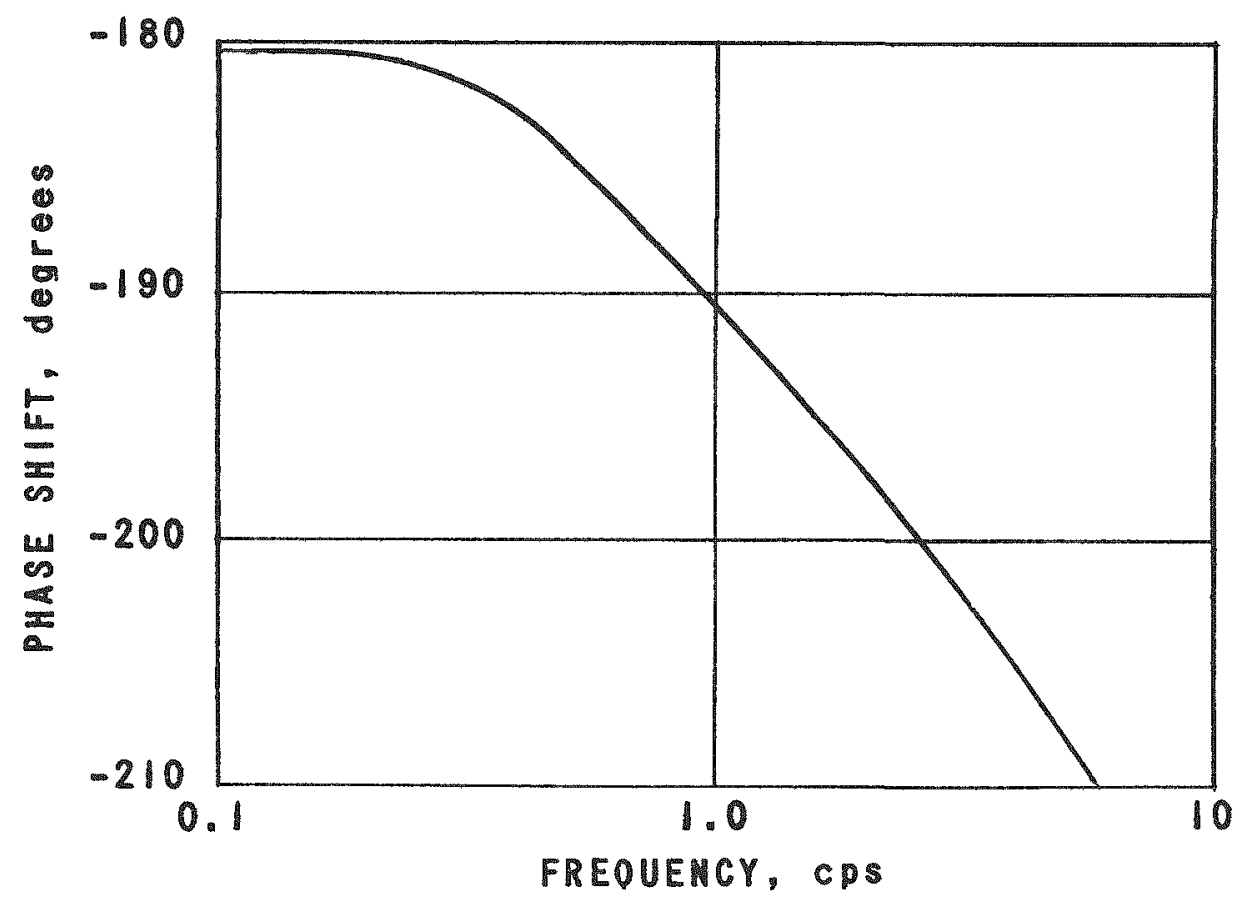

FIG. 24

OVER-ALL PHASE SHIFT DEMODULATED OUTPUT/MODULATION OF CARRIER INPUT

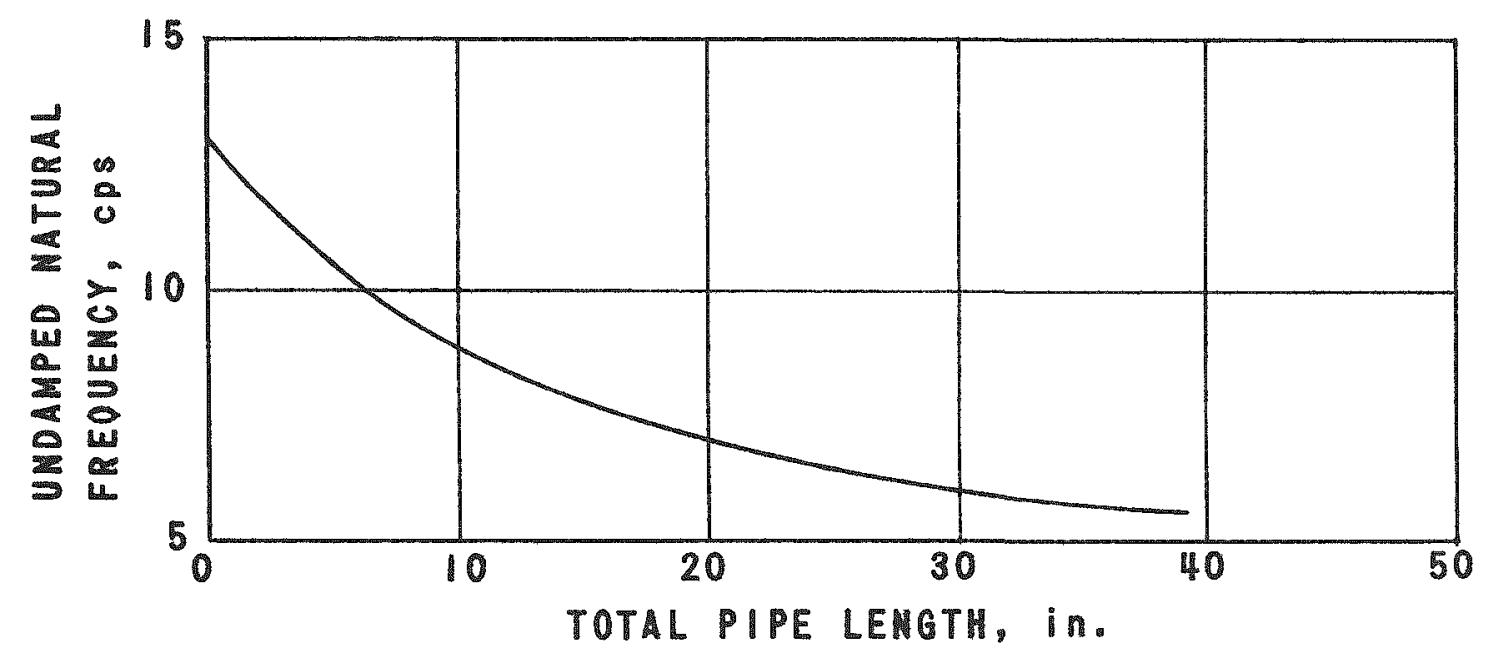

FIG. 25

NATURAL FREQUENCY OF FLOW METER VS LENGTH OF 1/2-inch CONNECTING PIPE 


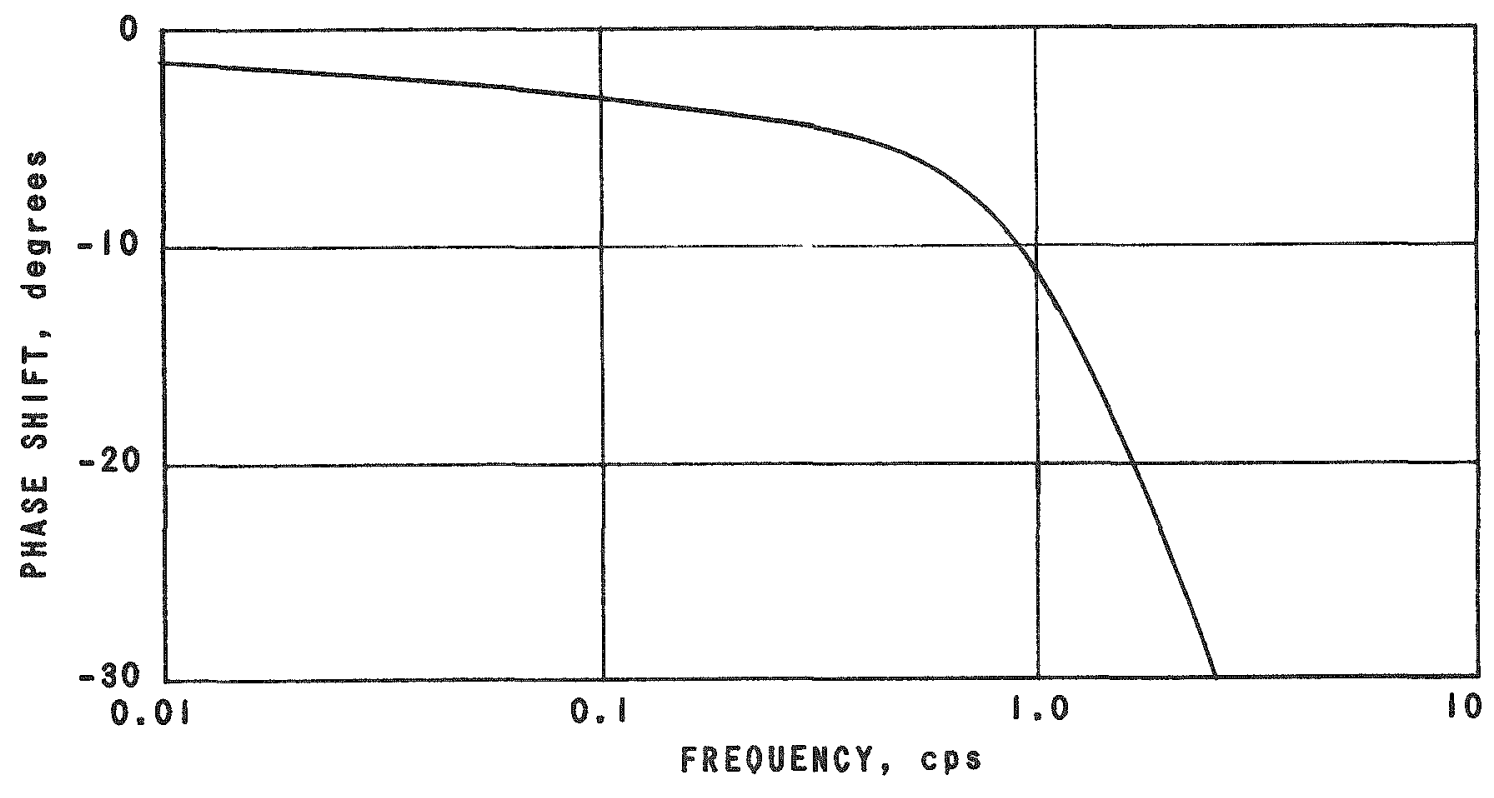

FIG. 26

PHASE SHIFT OF TRANSOUCER ANO AMPLIFIER WITH

THREE FEET OF $1 / 2$-inCh PIPE CONNECTIONS

AND VALVE SET FOR DAMPING RATIO $=0.4$

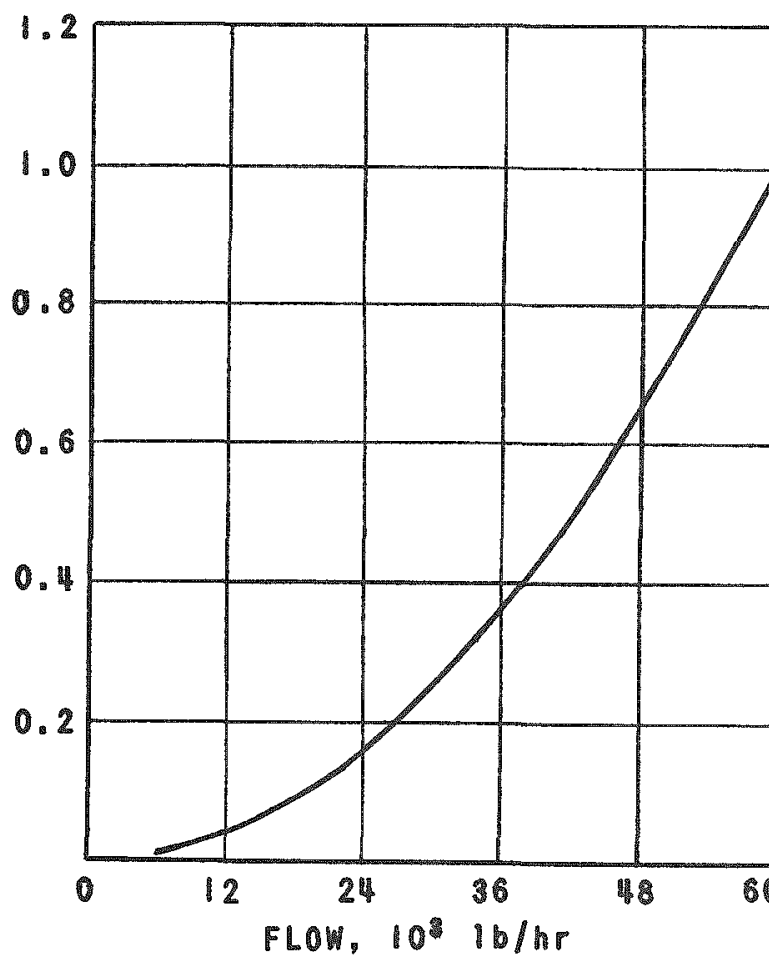

\begin{tabular}{|c|c|c|}
\hline $\begin{array}{c}\text { REACTOR } \\
\text { PRESSURE }\end{array}$ & $\begin{array}{c}\text { STEAM FLOW } \\
\text { WOZZLE }\end{array}$ & $\begin{array}{c}\text { WATER FLOW } \\
\text { NOZZLE }\end{array}$ \\
\hline 600 & $y=\frac{\Delta P}{73.4}$ & $y=\frac{\Delta P}{36}$ \\
\hline 300 & $y=\frac{\Delta P}{147}$ & $Y=1$ \\
\hline
\end{tabular}

$\triangle P=$ DIFFEREMTIAL MOZZLE

PRESSURE, in. $\mathrm{H}_{2} \mathrm{O}$.

F16.27

DIFFERENTIAL PRESSURE OF EBWR FLOW NOZZLES 
The feed-water flow meter installation and the steam flow meter installation are shown in Figures 28 and 29, respectively.

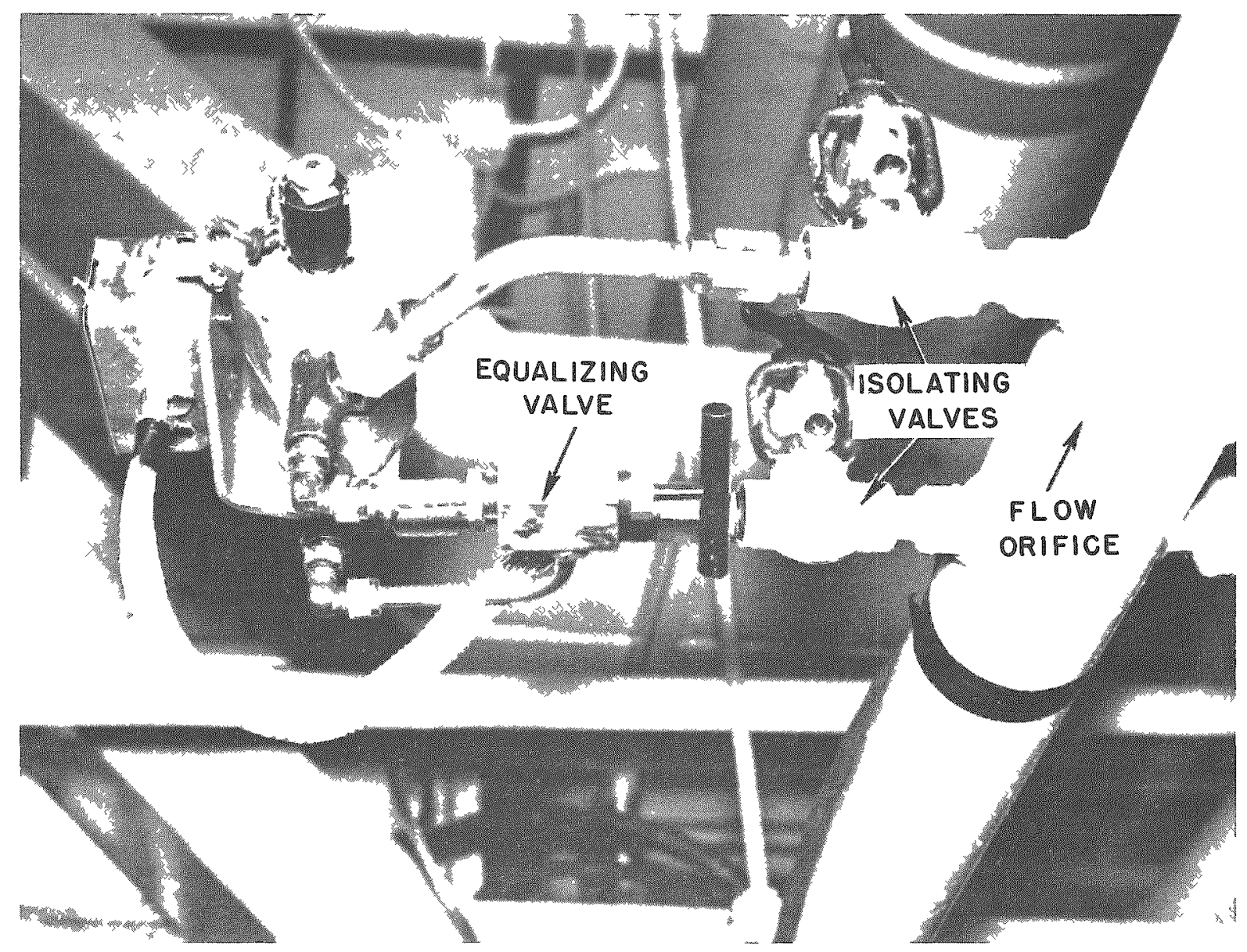

F. 28

FEEDWATER FLOWMETER INSTALLATION

\section{Pressure Measurement}

The pressure measurement was made with a transducer which consisted of a variable capacitance formed by an electrode and a draphragm that separated the electrode from the fluid or gas. Pressure varied the position of the diaphragm with respect to the electrode, thus varying the capacitance, which formed part of an $\mathrm{L}-\mathrm{C}$ crrcuit. The remainder of the instrument consisted of an oscillator, the $\mathrm{L}-\mathrm{C}$ curcuit slightly detuned, an amplifier, and a rectifier. The crystal-controlled oscillator pulsed the L-C circuit. As pressure varied, the tank tuning varied and the output 


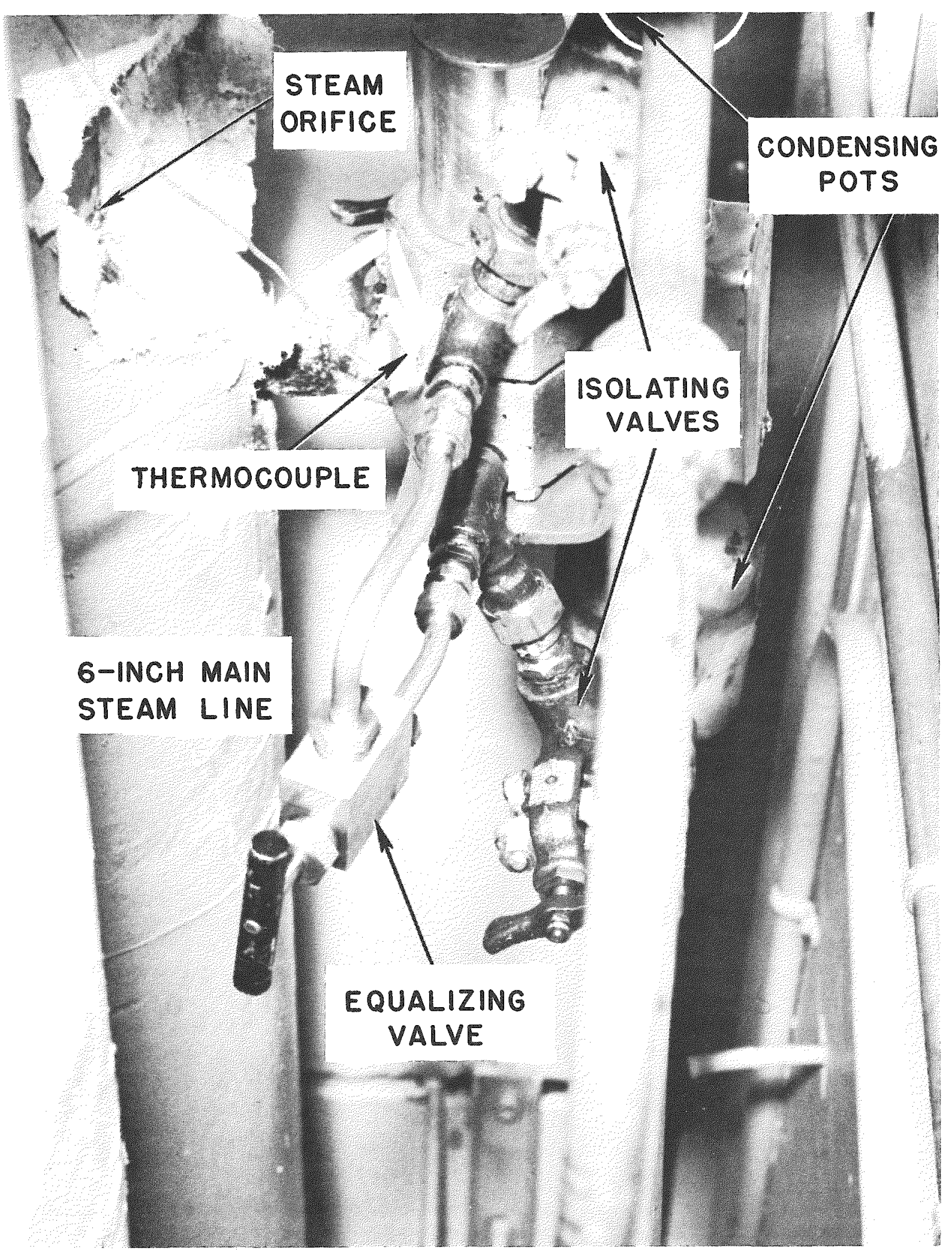

FIG. 29

STEAM FLOWMETER INSTALLATION 
voltage varied linearly with pressure over a wide range. A commercial instrument performed satisfactorly for large pressure signal measurements, but was inadequate for signals of less than a few per cent because of a large and erratic drift of the d-c output signal. This unit was modified as shown schematically in Fig. 30. The changes included:

(1) Replacement of power supply with regulated units

(2) Substitution of a semi-conductor diode for the thermionic diode demodulator

(3) Replacement of temperature-sensitive components

(4) Re-design of oscillator circuit

(5) Elimination of heater-cathode capacity of the buffer stage

(6) Substitution of a high-gain operational amplifier for the output stage.

The pressure instrumentation is shown pictorially in Fig. 31.

The sensitivity depended upon the diaphragm spring constant; with the 0.04 -inch diaphragm, the sensitivity at 600 psi was 5 millivolts/psi. A 60-cps rejection filter at the output was desirable for elimination of hum. Frequency response was limited by the filter characteristics.

A dead-weight tester (Fig. 31) was used for incremental pressure calibration. The transition from hydraulic oil in the tester to water in the pressure line was made by means of the inverted "U" tubing and pipe connection. 


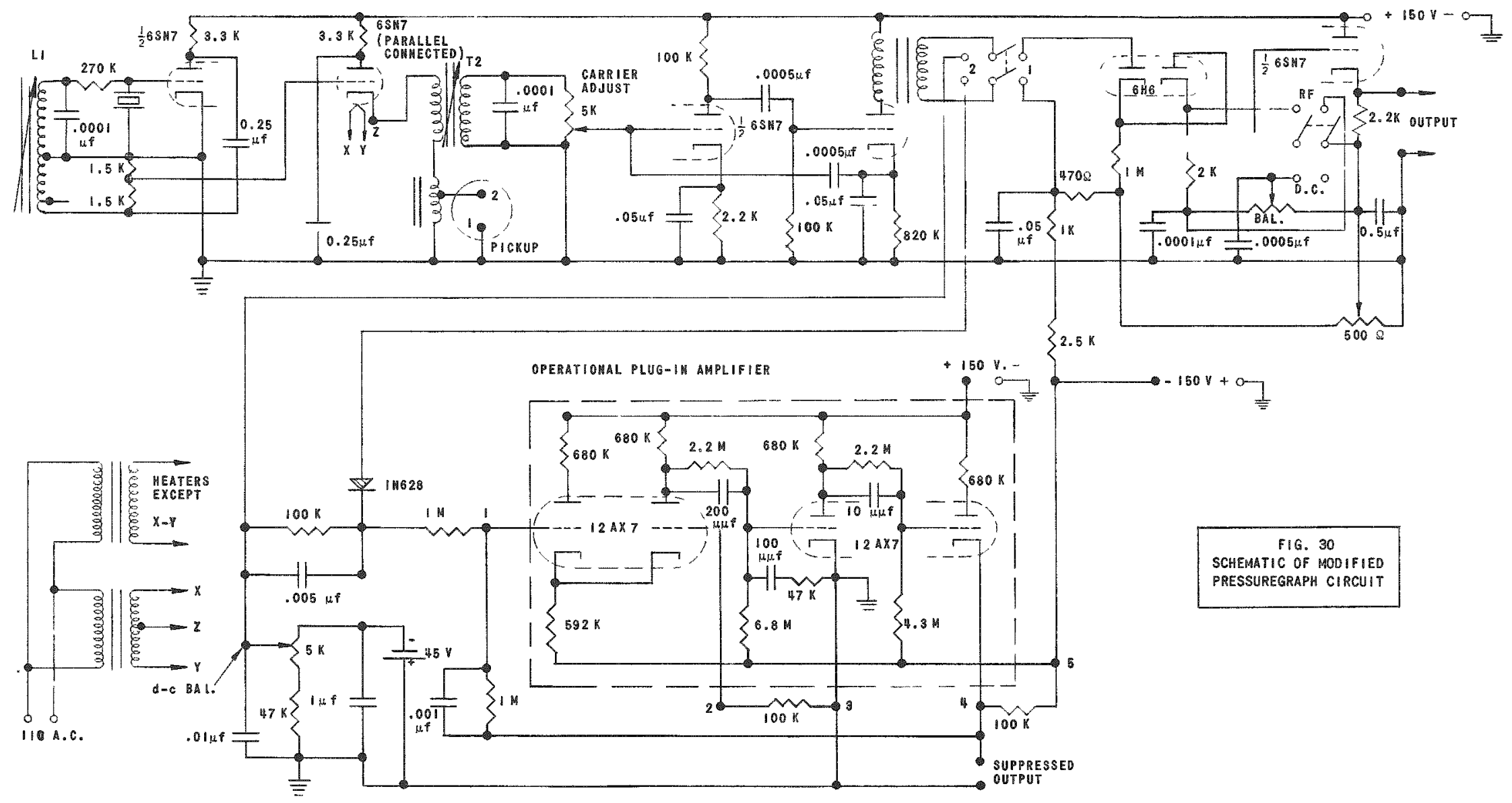




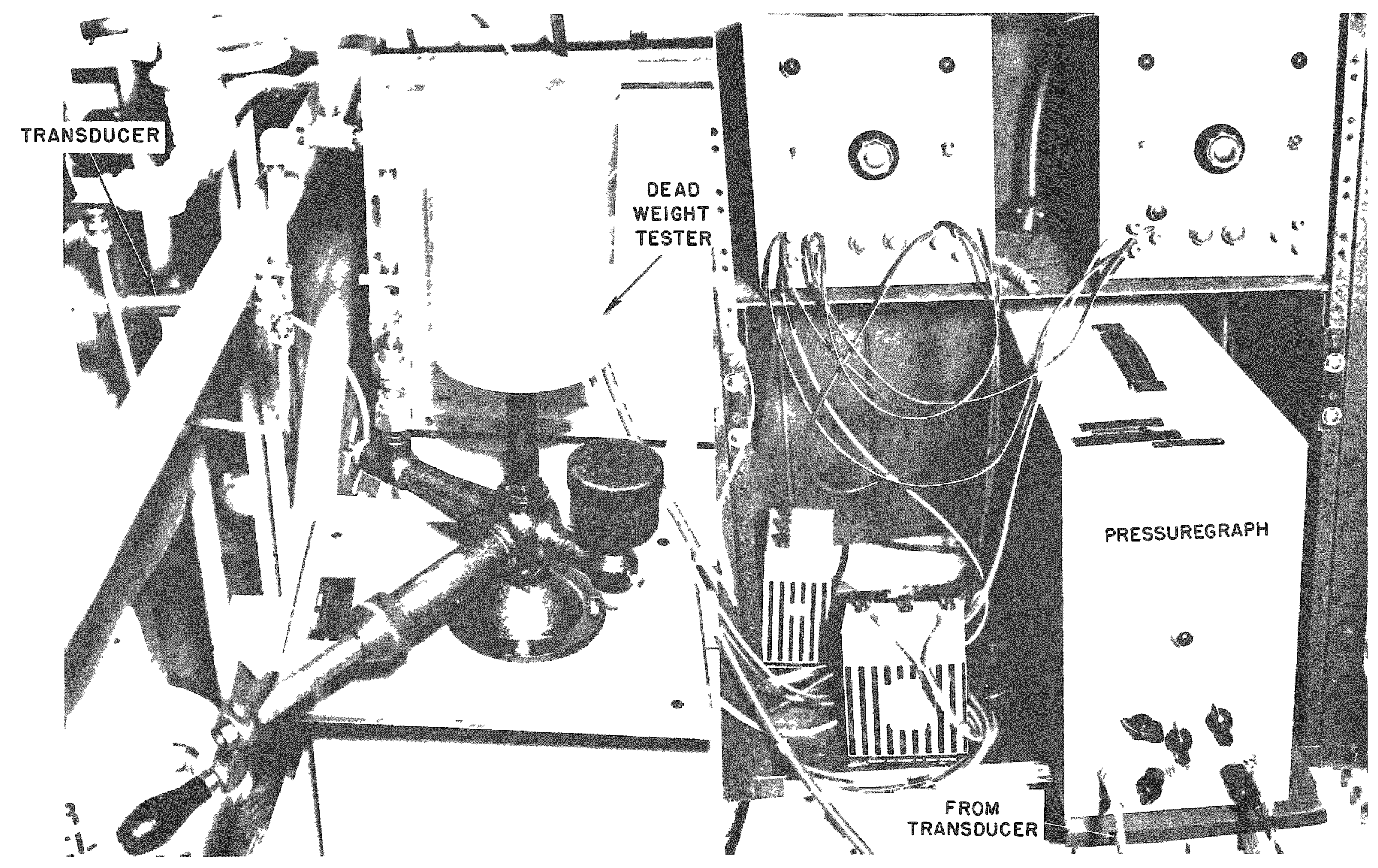

FIG. 31

PRESSURE INSTRUMENTATION 
The author acknowledges the assistance of R. V. Batch who designed the Reactivity Generator; A. Hirsch who designed the Wave Analyzer; E. S. Beckjord who designed the Steam Instrumentation; and J. M. Harrer who co-ordinated over-all reactor operations. 